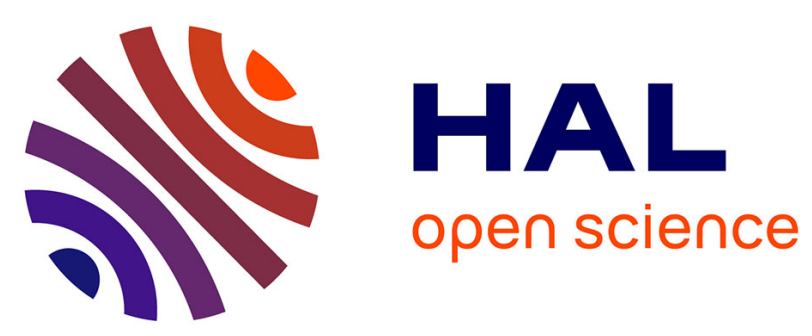

\title{
GFAT1 phosphorylation by AMPK promotes VEGF-induced angiogenesis
}

Darya Zibrova, Franck Vandermoere, Olga Göransson, Mark Peggie, Karina

Mariño, Anne Knierim, Katrin Spengler, Cora Weigert, Benoît Viollet, Nicholas A Morrice, et al.

\section{To cite this version:}

Darya Zibrova, Franck Vandermoere, Olga Göransson, Mark Peggie, Karina Mariño, et al.. GFAT1 phosphorylation by AMPK promotes VEGF-induced angiogenesis. Biochemical Journal, 2017, 474 (6), pp.983-1001. 10.1042/BCJ20160980 . hal-02366087

\section{HAL Id: hal-02366087 https://hal.science/hal-02366087}

Submitted on 15 Nov 2019

HAL is a multi-disciplinary open access archive for the deposit and dissemination of scientific research documents, whether they are published or not. The documents may come from teaching and research institutions in France or abroad, or from public or private research centers.
L'archive ouverte pluridisciplinaire HAL, est destinée au dépôt et à la diffusion de documents scientifiques de niveau recherche, publiés ou non, émanant des établissements d'enseignement et de recherche français ou étrangers, des laboratoires publics ou privés. 


\section{BIOCHEMICAL JOURNAL ACCEPTED MANUSCRIPT}

\section{GFAT1 phosphorylation by AMPK promotes VEGF-induced angiogenesis}

Darya Zibrova, Franck Vandermoere, Olga Göransson, Mark Peggie, Karina Mariño, Anne Knierim, Katrin Spengler, Cora Weigert, Benoit Viollet, Nicholas A. Morrice, Kei

Sakamoto, Regine Heller

Activation of AMP-activated protein kinase (AMPK) in endothelial cells regulates energy homeostasis, stress protection and angiogenesis, but the underlying mechanisms are incompletely understood. Using a label-free phosphoproteomic analysis, we identified glutamine:fructose-6-phosphate amidotransferase 1 (GFAT1) as an AMPK substrate. GFAT1 is the rate-limiting enzyme in the hexosamine biosynthesis pathway (HBP) and as such controls the modification of proteins by $O$-linked $\cdot$-N-acetylglucosamine $(O$ GlcNAc). In the present study, we tested the hypothesis that AMPK controls $O$-GlcNAc levels and function of endothelial cells via GFAT1 phosphorylation using biochemical, pharmacological, genetic and in vitro angiogenesis approaches. Activation of AMPK in primary human endothelial cells by 5 - aminoimidazole-4-carboxamide riboside (AICAR) or by vascular endothelial growth factor (VEGF) led to GFAT1 phosphorylation at serine 243. This effect was not seen when AMPK was downregulated by siRNA. Upon AMPK activation, diminished GFAT activity and reduced OGlcNAc levels were observed in endothelial cells containing wild-type (WT)-GFAT1 but not in cells expressing nonphosphorylatable S243A-GFAT1. Pharmacological inhibition or siRNAmediated downregulation of GFAT1 potentiated VEGF-induced sprouting indicating that GFAT1 acts as negative regulator of angiogenesis. In cells expressing S243A-GFAT1, VEGFinduced sprouting was reduced suggesting that VEGF relieves the inhibitory action of GFAT1/HBP on angiogenesis via AMPK-mediated GFAT1 phosphorylation.

Activation of GFAT1/HBP by high glucose led to impairment of vascular sprouting, while GFAT1 inhibition improved sprouting even if glucose level was high. Our findings provide novel mechanistic insights into the role of HBP in angiogenesis. They suggest that targeting AMPK in endothelium might help to ameliorate hyperglycaemia-induced vascular dysfunction associated with metabolic disorders.

Cite as Biochemical Journal (2016) DOI: 10.1042/BCJ20160980

Copyright 2016 The Author(s).

Use of open access articles is permitted based on the terms of the specific Creative Commons Licence under which the article is published. Archiving of non-open access articles is permitted in accordance with the Archiving Policy of Portland Press (http://www.portlandpresspublishing.com/content/open-access-policy\#Archiving). 


\section{GFAT1 phosphorylation by AMPK promotes VEGF-induced angiogenesis}

Darya Zibrova ${ }^{1, \S}$, Franck Vandermoere ${ }^{2, \S}$, Olga Göransson ${ }^{3}$, Mark Peggie ${ }^{4}$, Karina Mariño ${ }^{5}$, Anne Knierim ${ }^{1}$, Katrin Spengler ${ }^{1}$, Cora Weigert ${ }^{6,7,8}$, Benoit Viollet ${ }^{9,10,11}$, Nicholas A. Morrice ${ }^{12}$, Kei Sakamoto ${ }^{13, \#, \text {, Regine Heller }}{ }^{1, \boldsymbol{\eta}, *}$

${ }^{1}$ Institute of Molecular Cell Biology, Center for Molecular Biomedicine, Jena University Hospital, 07745 Jena, Germany

${ }^{2}$ Institut de Génomique Fonctionnelle, CNRS UMR5203, INSERM U1191, Université de Montpellier, France

${ }^{3}$ Department of Experimental Medical Sciences, Lund University, 22184 Lund, Sweden

${ }^{4}$ Division of Signal Transduction Therapy, College of Life Sciences, University of Dundee, Dundee DD1 5EH, Scotland, UK

${ }^{5}$ Laboratorio de Glicómica Funcional y Molecular, Instituto de Biología y Medicina Experimental, Consejo Nacional de Investigaciones Científicas y Técnicas (IBYME-CONICET), C1428 Buenos Aires, Argentina

${ }^{6}$ Division of Pathobiochemistry and Clinical Chemistry, University of Tübingen, 72076 Tübingen, Germany

${ }^{7}$ Institute for Diabetes Research and Metabolic Diseases of the Helmholtz Zentrum München at the University of Tübingen, 72076 Tübingen, Germany

${ }^{8}$ German Center for Diabetes Research (DZD), 85764 Neuherberg, Germany

${ }^{9}$ INSERM U1016, Institut Cochin, Paris, France

${ }^{10}$ CNRS UMR 8104, Paris, France

${ }^{11}$ Université Paris Descartes, Sorbonne Paris Cité, Paris, France

${ }^{12}$ AB-Sciex, Phoenix House, Centre Park, Warrington WA1 1RX, UK 
${ }^{13}$ MRC Protein Phosphorylation and Ubiquitylation Unit, College of Life Sciences, University of Dundee, Dundee DD1 5EH, Scotland, UK

${ }^{\#}$ Current address: Nestlé Institute of Health Sciences SA, EPFL Innovation Park, bâtiment H, 1015 Lausanne, Switzerland

${ }^{\S}$ Co-first author

"co-senior author

*Corresponding author: Dr. Regine Heller

Institute for Molecular Cell Biology, Center for Molecular Biomedicine, Jena University Hospital

Hans-Knöll-Straße 2

07745 Jena

Germany

Telefon +49 (0)3641-9395633

Telefax $+49(0) 3641-9395602$

E-mail: regine.heller@med.uni-jena.de 


\section{Abstract}

Activation of AMP-activated protein kinase (AMPK) in endothelial cells regulates energy homeostasis, stress protection and angiogenesis, but the underlying mechanisms are incompletely understood. Using a label-free phosphoproteomic analysis, we identified glutamine:fructose-6-phosphate amidotransferase 1 (GFAT1) as an AMPK substrate. GFAT1 is the rate-limiting enzyme in the hexosamine biosynthesis pathway (HBP) and as such controls the modification of proteins by $O$-linked $\beta$-N-acetylglucosamine $(O$-GlcNAc). In the present study, we tested the hypothesis that AMPK controls $O$-GlcNAc levels and function of endothelial cells via GFAT1 phosphorylation using biochemical, pharmacological, genetic and in vitro angiogenesis approaches. Activation of AMPK in primary human endothelial cells by 5aminoimidazole-4-carboxamide riboside (AICAR) or by vascular endothelial growth factor (VEGF) led to GFAT1 phosphorylation at serine 243. This effect was not seen when AMPK was downregulated by siRNA. Upon AMPK activation, diminished GFAT activity and reduced $O$ GlcNAc levels were observed in endothelial cells containing wild-type (WT)-GFAT1 but not in cells expressing non-phosphorylatable S243A-GFAT1. Pharmacological inhibition or siRNAmediated downregulation of GFAT1 potentiated VEGF-induced sprouting indicating that GFAT1 acts as negative regulator of angiogenesis. In cells expressing S243A-GFAT1, VEGFinduced sprouting was reduced suggesting that VEGF relieves the inhibitory action of GFAT1/HBP on angiogenesis via AMPK-mediated GFAT1 phosphorylation. Activation of GFAT1/HBP by high glucose led to impairment of vascular sprouting, while GFAT1 inhibition improved sprouting even if glucose level was high. Our findings provide novel mechanistic insights into the role of HBP in angiogenesis. They suggest that targeting AMPK in endothelium might help to ameliorate hyperglycaemia-induced vascular dysfunction associated with metabolic disorders. 


\section{Summary statement}

AMPK is an important regulator of endothelial function; however, the underlying mechanisms are poorly understood. In the present study, we demonstrate that AMPK decreases $O$-GlcNAc levels in human endothelial cells via GFAT1 phosphorylation thereby promoting VEGF-induced angiogenesis.

Short title: GFAT1 mediates pro-angiogenic AMPK effects

Key words: AMPK; angiogenesis; GFAT1; $O$-GlcNAcylation; phosphoproteomics; VEGF

Abbreviations: ACC, acetyl-CoA carboxylase; AMPK, AMP-activated protein kinase; DON, 6diazo-5-oxo-L-norleucine; GFAT, glutamine:fructose-6-phosphate amidotransferase; HBP, hexosamine biosynthesis pathway; HAS, human serum albumin; HUVEC, human umbilical cord vein endothelial cells; IMAC, immobilised metal affinity chromatography; MEF, mouse embryonic fibroblasts; $O$-GlcNAc, $O$-linked $\beta$-N-acetylglucosamine; $\mathrm{TiO}_{2}$, titanium dioxide; TSC, tuberous sclerosis complex; UDP-GlcNAc, UDP- $N$-acetylglucosamine; VEGF, vascular endothelial growth factor; WT, wild-type. 


\section{Introduction}

AMPK is an important component of signalling mechanisms regulating energy and nutrient metabolism. It is a heterotrimeric serine/threonine protein kinase consisting of catalytic $\alpha$ and regulatory $\beta$ and $\gamma$ subunits, each existing as several isoforms [1]. Energy-depriving stresses or pharmacological agents, which increase AMP/ATP and ADP/ATP ratios, trigger binding of AMP to the $\gamma$ subunit and activate AMPK via a triple mechanism: (i) allosteric activation, (ii) phosphorylation of threonine 172 on the activation loop of AMPK $\alpha$ and (iii) inhibition of dephosphorylation of threonine 172 [2-4]. The upstream kinases of AMPK include LKB1 in response to metabolic stress and $\mathrm{Ca}^{2+} /$ calmodulin-dependent protein kinase kinase 2 in response to $\mathrm{Ca}^{2+}$-elevating agonists (reviewed in [1]). AMPK maintains cellular ATP homeostasis by activating ATP-producing pathways and by inhibiting ATP-consuming pathways via phosphorylation of target proteins such as acetyl-CoA carboxylase isoforms 1 and 2, which regulate fatty acid synthesis and oxidation, respectively [5, 6]. Furthermore, it serves as a metabolic checkpoint for cell growth by inhibiting mammalian target-of-rapamycin complex-1 $[7,8]$.

AMPK plays an important role in endothelial cells. It is activated by a variety of stimuli including shear stress, oxidants, hormones, vascular mediators and VEGF (reviewed in [9]). Activation of AMPK in endothelial cells seems to be associated with regulation of energy supply, stress protection, maintenance of anti-inflammatory and anti-atherogenic phenotypes and regulation of angiogenesis [10] but the underlying mechanisms are not fully elucidated. To further understand cellular functions of AMPK, the identification and characterisation of novel AMPK substrates is therefore of high importance.

Recent studies suggested GFAT1 as a new AMPK target while GFAT2, predominantly expressed in the central nervous system [11], was not found in screens for novel AMPK substrates [12-14]. GFAT1 is ubiquitously expressed and catalyses the formation of glucosamine-6-phosphate, the first product of the HBP, using fructose-6-phosphate and L- 
glutamine as substrates. This step is rate-limiting for the synthesis of UDP- $N$-acetylglucosamine (UDP-GlcNAc), the end product of the HBP. UDP-GlcNAc is used as donor for adding $N$ acetylglucosamine to serine/threonine residues of proteins. This post-translational modification known as $O$-GlcNAcylation modulates key biological processes such as transcription, signal transduction and cytoskeletal reorganisation [15]. GFAT is activated by high extracellular glucose, and studies using genetically modified mice demonstrated a causative link between GFAT1 activity and diabetic state [16-18]. Moreover, GFAT1 activity was shown to be elevated in diabetic patients [19]. The increase in $O$-GlcNAcylation of proteins as a consequence of GFAT activation is thought to contribute to the development of insulin resistance [20] and endothelial dysfunction [21], which is an initial event in atherogenesis and a hallmark of vascular complications of type 2 diabetes.

Despite the importance of the HBP in providing the substrate for $O$-GlcNAcylation, the posttranslational regulation of the key enzyme GFAT is incompletely understood. GFAT1 has been reported to be an AMPK substrate with serine 243 as putative phosphorylation site, which was shown to be activating in vitro [13], but inhibitory in certain cellular context [12]. However, detailed biochemical characterisation of AMPK-dependent GFAT1 phosphorylation and the functional role of this pathway in physiologically relevant systems have not been established. Therefore, in the present study we address the role of GFAT1 regulation by AMPK in primary human endothelial cells. We demonstrate that GFAT1 is a component of the VEGF-AMPK pathway in endothelial cells and, as such, a mediator of pro-angiogenic effects of AMPK. Via GFAT1 phosphorylation, AMPK can decrease $O$-GlcNAcylation of proteins, which may also contribute to beneficial metabolic outcomes of AMPK activation, thus further underlining the importance of AMPK as a drug target. 


\section{Experimental procedures}

\section{Materials}

Cell culture media and sera were from Lonza. Endothelial mitogen was from Hycultec GmbH. Human plasma fibrinogen (341576) was purchased from Calbiochem. Proteinase inhibitor mixture complete, EDTA-free, was acquired from Roche Diagnostics. Mass spectrometry grade trypsin (Trypsin Gold, V5280) was from Promega. KOD Hot Start Polymerase and pSC-b vector were purchased from Novagen and Stratagene, respectively. Colloidal Blue and LDS sample loading buffer were from Life Technologies. DC ${ }^{\mathrm{TM}}$ Protein Assay kit was from Bio-Rad Laboratories. Recombinant human VEGF-165 was purchased from R\&D Systems GmbH. The AMPK activator A-769662 was synthesized either as previously described [22] or obtained from Abcam Biochemicals (ab120335). 5-aminoimidazole-4-carboxamide riboside (AICAR, ab120358) was from Abcam Biochemicals. Protein G Sepharose (P3296) and PHOS-Select ${ }^{\mathrm{TM}}$ Iron Affinity Gel were from Sigma-Aldrich. Glutathione sepharose resin and $\mathrm{ECL}^{\mathrm{TM}}$ Western Blotting Detection kit were from GE Healthcare. Titansphere $5 \mu \mathrm{m}$ loose beads were from Hichrom Limited. SAINT-RED was from Synvolux Therapeutics B.V. Unless otherwise indicated all other reagents were from Sigma-Aldrich.

\section{Antibodies}

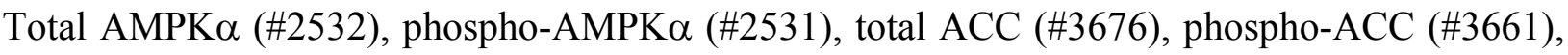
and $\beta$-actin (\#4970) antibodies were from Cell Signalling Technology. O-GlcNAc antibody (CTD110.6 clone, \#MMS-248R) was from Biolegend Covance. GFAT1 rabbit antiserum was generated as described previously [23]. Polyclonal sheep antibody against AMPK $\alpha 1$ and glutathione S-transferase (GST) antibody were kindly provided by Dr. D. Grahame Hardie (University of Dundee). Polyclonal sheep antibody against GFAT1 (S702C, $3^{\text {rd }}$ bleed) and sitespecific sheep polyclonal antibody against phospho-(Ser243)-GFAT1 (S343C, $3^{\text {rd }}$ bleed) were generated in the Division of Signal Transduction Therapy (University of Dundee, UK) by 
immunization with a full-length human GST-GFAT1 or phosphorylated peptide of the human sequence (residues 240-251 [RVDS*TTCLFPVE, * indicates the phospho-serine]), respectively. Horseradish peroxidase (HRP)-conjugated secondary antibody to rabbit and sheep IgG were from Kirkegaard \& Perry Laboratories, Inc. (KPL) and Santa Cruz Biotechnology, Inc., respectively. HRP-conjugated secondary antibody to mouse $\operatorname{IgM} \mu$ chain (\#074-1803) was from KPL.

\section{Oligos}

The primers used for site-directed mutagenesis of GFAT1 were:

MP4146 CTCTCTCGTGTGGACGCCACAACCTGCCTTTTC (forward)

MP4147 GAAAAGGCAGGTTGTGGCGTCCACACGAGAGAG (reverse).

The siRNA duplex oligonucleotides used in this study were based on the human cDNAs encoding AMPK $\alpha 1$, AMPKa2, and GFAT1. AMPK $\alpha 1$ - and AMPK $\alpha 2$-specific SMARTpool siRNA reagents (M-005027-02-0020 and M-005361-02-0020, respectively) were purchased from Dharmacon (GE Healthcare). For GFAT1, 5'-GGAGGAUACUGAGACCAUU-3' (sense) and 3'-CCUCCUAUGACUCUGGUAA-5' (anti-sense) siRNA duplex oligonucleotides, reported by Jokela et al. [24], were obtained from Sigma. A nonspecific control SMARTpool siRNA (D001810-10-20) was from Dharmacon.

\section{Mouse embryonic fibroblasts}

WT (AMPK $\alpha 1^{+/+} \alpha 2^{+/+}$) and AMPK-deficient (AMPK $\alpha 1^{-/-} \alpha 2^{-/-}$) mouse embryonic fibroblasts (MEFs) were generated as previously described [25]. The animal study was approved by the Paris Descartes University ethics committee (no. CEEA34.BV.157.12) and performed under French authorization to experiment on vertebrates (no. 75-886) in accordance with the European guidelines. MEFs were maintained in DMEM containing $4.5 \mathrm{~g} / \mathrm{l}$ glucose, $10 \%$ foetal calf serum 
(FCS), $2 \mathrm{mmol} / \mathrm{l}$ glutamine, $50 \mathrm{U} / \mathrm{ml}$ penicillin and $50 \mu \mathrm{g} / \mathrm{ml}$ streptomycin (DMEM culture medium).

\section{Phosphoproteomic screen for AMPK substrates in cells}

After treatment of AMPK $\alpha 1^{+/+} \alpha 2^{+/+}$and AMPK $\alpha 1^{-/-} \alpha 2^{-/-}$MEFs with A-769662 (100 $\mu \mathrm{mol} / 1,1$ h), protein lysates were obtained and trypsin digested. Phosphopeptides were enriched and analysed by LC-MS/MS. Subsequently, phosphopeptides (1697 within 742 proteins) identified in

a Mascot search were checked for AMPK consensus sequence. The latter is based on a compromise between the sequence derived from established AMPK cellular substrates [26] and an in vitro peptide screen published by Gwinn et al: [M/V/L/F/I]-X(0,1)-[R/H/K]-X(2,3)-[S/T]$\mathrm{X}(3)-[\mathrm{M} / \mathrm{V} / \mathrm{L} / \mathrm{I} / \mathrm{F}]$, where $\mathrm{X}$ is any amino acid [7]. Matched peptides were relatively quantified using the height of the extracted ion chromatogram, which was compared between A-769662treated AMPK $\alpha 1^{+/+} / \alpha 2^{+/+}$and AMPK $\alpha 1^{-/-} / \alpha 2^{-/-}$MEFs. The detailed screening is reported in Supplementary Material, Methods.

\section{Cloning, site directed-mutagenesis}

Human GFAT1 (NCBI BC045641) was amplified from IMAGE EST 5298728 using KOD Hot Start Polymerase, cloned into pSC-b and sequenced to completion. The resulting plasmid was digested with BamH1 and Not1 and cloned between the same sites into vectors for bacterial (pGEX6P-1) and mammalian (pEBG6P) expression, encoding proteins with an N-terminal glutathione S-transferase (GST) tag. Site-directed mutagenesis was performed by the Stratagene Quickchange method but using KOD Hot Start DNA Polymerase.

For generation of lentiviral particles, cDNA sequences encoding WT- and S243A-GFAT1 were cut off respective pEBG6P vectors using BamH1 and Not1 and inserted between the same sites into pCDH-CMV-MCS-EF1-Puro lentivectors (CD510B-1, System Biosciences (SBI)) to 
generate

pCDH-CMV-MCS-EF1-Puro-GFAT1 and

pCDH-CMV-MCS-EF1-Puro-S243A-

GFAT1 plasmids for expression of untagged versions of either protein.

\section{In vitro phosphorylation of recombinant GFAT1}

WT or S243A mutant of human GST-tagged-GFAT1 were expressed in E. coli and purified using glutathione sepharose resin. Each recombinant protein $(1 \mu \mathrm{g})$ was treated with $5 \mathrm{U} / \mathrm{ml}$ of activated recombinant AMPK trimeric complex $(\alpha 2 \beta 2 \gamma 1)$ (kindly provided by Dr. D. Grahame Hardie, University of Dundee, UK), in $50 \mathrm{mmol} / 1$ Tris-HCl, $\mathrm{pH} 7.5$, containing $10 \mathrm{mmol} / 1 \mathrm{MgCl}_{2}$, $0.1 \mathrm{mmol} / 1 \mathrm{EGTA}, 0.1 \% \beta$-mercaptoethanol, and $0.1 \mathrm{mmol} / 1 \mathrm{ATP}$ for $5 \mathrm{~min}$ at $30^{\circ} \mathrm{C}$. When radioactive labelling was required, ATP was provided as $\left[\gamma_{-}{ }^{32} \mathrm{P}\right] \mathrm{ATP}(0.1 \mathrm{mmol} / \mathrm{l}$, GE Healthcare; $1,000-2,000 \mathrm{cpm} / \mathrm{pmol}$ in analytical kinase assays, approx. $10,000 \mathrm{cpm} / \mathrm{pmol}$ for phosphorylation site analysis). Reaction was stopped by boiling samples for $5 \mathrm{~min}$ in LDS sample loading buffer. The proteins were subjected to electrophoresis on polyacrylamide gels followed by Colloidal Blue staining. GFAT1, which was evident as a $110 \mathrm{kDa}$ band after staining and autoradiography, was excised, and the amount of ${ }^{32} \mathrm{P}$ incorporation was determined by Cerenkov counting. The stoichiometry of GFAT1 phosphorylation at serine 243 site was estimated based on the following calculations: $\left[\gamma_{-}{ }^{32} \mathrm{P}\right] \mathrm{ATP}$ had a specific activity of 10,000 $\mathrm{cpm} / \mathrm{pmol}$. Since fusion GST-GFAT1 protein weights $104 \mathrm{kDa}, 1 \mu \mathrm{g}$ of this protein used for the kinase assay, corresponded to $9.6 \mathrm{pmol}\left(1 \times 10^{-6} / 104,000=9.6 \times 10^{-12} \mathrm{~mol}\right)$. After a kinase assay and SDS-PAGE, the GFAT band excised from the gel showed a radioactivity count of $32,000 \mathrm{cpm}$, meaning that 3.2 pmol $(32,000 / 10,000)$ of phosphate was transferred to the 9.6 pmol of GFAT protein, i. e. $33 \%$ of GFAT protein copies were phosphorylated after 5 min of kinase assay.

For phosphosite mapping, the protein was reduced with $10 \mathrm{mmol} / \mathrm{l}$ DTT, alkylated with iodoacetamide $(50 \mathrm{mmol} / 1$ in $0.1 \mathrm{~mol} / 1$ ammonium bicarbonate) and digested with trypsin (5 $\mu \mathrm{g} / \mathrm{ml}$ protease in $25 \mathrm{mmol} / 1$ triethylammonium bicarbonate). The resulting peptides were applied to a Vydac 218TP215 C18 column equilibrated with $0.1 \%$ trifluoroacetic acid (TFA) and 
the column was developed with a linear gradient of acetonitrile $/ 0.1 \%$ TFA at a flow rate of 0.2 $\mathrm{ml} / \mathrm{min}$ with $0.1 \mathrm{ml}$ fractions collected. ${ }^{32} \mathrm{P}$ radioactivity was recorded with an on-line monitor. Identification of phosphorylated peptides present in the radioactive fraction was performed by mass spectrometry.

\section{Primary endothelial cell culture and treatment conditions}

Human umbilical vein endothelial cells (HUVEC) were isolated from anonymously acquired umbilical cords according to the Declaration of Helsinki "Ethical principles for Medical Research Involving Human Subjects" (1964). The study was approved by the Jena University Hospital ethics committee (no. 3950-12/13). The donors were informed and gave written consent. The study comprises data obtained in approximately 50 different HUVEC batches (3-5 individual batches per experimental setting). In general, cells of the first or second passage were used, for experiments with genetic modification first to third passage cells were included.

HUVEC were prepared and cultured in M199 containing $17.5 \%$ fetal calf serum (FCS), 2.5\% human serum, and $7.5 \mu \mathrm{g} / \mathrm{ml}$ endothelial mitogen as described previously [27]. Prior to stimulation, HUVEC were serum-starved in M199 containing 0.25\% human serum albumin (HSA) for $4 \mathrm{~h}$. Subsequently, $2 \mathrm{mmol} / \mathrm{l}$ AICAR or vehicle was added for $1 \mathrm{~h}$ if not specified. Alternatively, VEGF stimulation (50 $\mathrm{ng} / \mathrm{ml}, 5 \mathrm{~min}$ if not specified) was performed in Hepes buffer $(10$ mmol/1 Hepes, pH 7.4, 145 mmol/1 NaCl, 5 mmol/1 KCl, 1 mmol/1 MgSO 4,10 mmol/1 glucose) supplemented with $1.5 \mathrm{mmol} / 1 \mathrm{CaCl}_{2}$ and $0.25 \% \mathrm{HSA}$. The VEGF concentrations used in the present study (10 and $50 \mathrm{ng} / \mathrm{ml}$ for spheroid and biochemical assays, respectively) were previously shown to be plateau concentrations for AMPK activation in endothelial cells [10, 28] and angiogenesis [10]. To investigate glucose-dependency, M199 growth medium containing either normal $(5.5 \mathrm{mmol} / \mathrm{l})$ or high $(25 \mathrm{mmol} / \mathrm{l})$ glucose was used. Treatment of HUVEC with GFAT1 antagonist 6-diazo-5-oxo-L-norleucine (DON) was performed in M199 growth medium for 24-72 h. The applied DON concentration of $100 \mu \mathrm{mol} / \mathrm{l}$ is in the upper range of what is 
frequently used in the literature [29, 30] but did not induce adverse effects on HUVEC viability and proliferation.

\section{Cell lysis and immunoprecipitation}

Following the respective treatments, cells were washed with PBS and lysed on ice with buffer containing 50 mmol/1 Tris (pH 7.5), 1 mmol/1 EDTA, 1 mmol/1 EGTA, 1\% (v/v) Triton X-100, 1 $\mathrm{mmol} / 1 \quad \mathrm{Na}_{3} \mathrm{VO}_{4}, 50 \mathrm{mmol} / \mathrm{l} \mathrm{NaF}, 5 \mathrm{mmol} / 1 \quad \mathrm{Na}_{4} \mathrm{P}_{2} \mathrm{O}_{7}, 0.27 \mathrm{~mol} / \mathrm{l}$ sucrose, $0.1 \%$ (v/v) $\beta$ mercaptoethanol, $0.2 \mathrm{mmol} / 1 \mathrm{PMSF}, 1 \%$ complete protease inhibitor cocktail (Roche) and 40 $\mu \mathrm{mol} / 1$ PUGNAc (for $O$-GlcNAc blots). After centrifugation $\left(13,000 \mathrm{x} \mathrm{g}, 10 \mathrm{~min}, 4^{\circ} \mathrm{C}\right.$ ) protein concentrations were determined using Lowry reagents ( $\mathrm{DC}^{\mathrm{TM}}$ Protein Assay kit) and bovine serum albumin (BSA) as standard.

For immunoprecipitation of recombinant GST-GFAT1, lysates (1 mg protein) were incubated with $2 \mu \mathrm{g}$ of anti-GST antibody. Endogenous GFAT was immunoprecipitated from cell lysates (0.2-1 mg) using $1 \mu \mathrm{l}$ of GFAT1 rabbit antiserum in the presence of $10 \mu \mathrm{l}$ of $50 \%$ protein $\mathrm{G}$ sepharose for $2 \mathrm{~h}$ at $4^{\circ} \mathrm{C}$ on a rotating wheel. Protein $\mathrm{G}$ sepharose beads with bound immune complexes were recovered at $6,000 \mathrm{~g}$ for $1 \mathrm{~min}$. Then, beads were washed sequentially on ice with lysis buffer plus $0.5 \mathrm{~mol} / \mathrm{l} \mathrm{NaCl}$, salt-free lysis buffer, and $50 \mathrm{mmol} / \mathrm{l}$ Tris- $\mathrm{HCl}(\mathrm{pH} 8.0)$ plus $0.1 \mathrm{mmol} / 1 \mathrm{EGTA}$, twice with each washing medium. The proteins were boiled in 25 $\mu 1 /$ pellet of $2 \mathrm{x} \mathrm{Laemmli} \mathrm{buffer} \mathrm{at} 95^{\circ} \mathrm{C}$ for $5 \mathrm{~min}$ and recovered at $16,000 \mathrm{xg}$ for $5 \mathrm{~min}$ at room temperature. The supernatants were analysed by immunoblotting.

\section{GFAT enzymatic activity assay}

Endothelial cells were lysed as described in the previous chapter except that $2 \mathrm{mM}$ DTT and 1 $\mathrm{mM}$ fructose-6-phosphate were included into the lysis buffer to stabilise the enzyme [31]. To separate GFAT from other glutaminases present in the cell lysate, GFAT was immunopurified as detailed above and the activity of GFAT was determined employing a spectrophotometric assay, 
in which glutaminase activity of GFAT is coupled to the glutamate dehydrogenase reaction [32]. Briefly, GFAT immunoprecipitates were resuspended in $100 \mu \mathrm{l}$ assay mixture consisting of 6 $\mathrm{mmol} / 1$ fructose-6-phosphate, $10 \mathrm{mmol} / \mathrm{l}$ glutamine (saturating concentrations for both substrates), $0.3 \mathrm{mmol} / 1$ 3-acetylpyridine adenine dinucleotide (APAD), $50 \mathrm{mmol} / \mathrm{K} \mathrm{KCl}, 100$ $\mathrm{mmol} / 1 \mathrm{KH}_{2} \mathrm{PO}_{4},(\mathrm{pH} 7.5), 1 \mathrm{mmol} / 1$ EDTA, and $6 \mathrm{U}$ of glutamate dehydrogenase. The assay was incubated at $37^{\circ} \mathrm{C}$ for $2 \mathrm{~h}$ with agitation and stopped by centrifugation at $13,000 \mathrm{x}$ g for $1 \mathrm{~min}$ to separate the protein $\mathrm{G}$ sepharose-bound enzyme from the substrates. Afterwards, the absorbance of supernatants due to reduction of APAD to APADH was monitored spectrophotometrically at $365 \mathrm{~nm}$. A standard curve was prepared using $0-25 \mathrm{nmol}$ glutamate [33]. A unit of activity was defined as $1 \mathrm{nmol}$ of glutamate formed per min. The remaining beads were used to control for GFAT equality and phosphorylation level in every sample.

\section{Immunoblotting}

Cell lysates (30-50 $\mu \mathrm{g} / \mathrm{lane})$, immunoprecipitates or samples of kinase reaction (10 $\mathrm{ng}$ ) were electrophoretically separated by SDS-PAGE and transferred onto PVDF membranes. The membranes were blocked for $1 \mathrm{~h}$ in TBST buffer $(20 \mathrm{mmol} / 1$ Tris $(\mathrm{pH} 7.6), 137 \mathrm{mmol} / \mathrm{l} \mathrm{NaCl}$, $0.1 \%(\mathrm{v} / \mathrm{v})$ Tween-20) containing $5 \%$ non-fat dried skimmed milk or $4 \%$ BSA (for $O$-GlcNAc blots). Membranes were incubated overnight at $4{ }^{\circ} \mathrm{C}$ with primary antibodies (plus nonphosphopeptide [RVDSTTCLFPVE] in case of phospho-GFAT1 antibody, 10:1 by mass). Antibody dilutions were prepared in TBST containing 5\% BSA, 5\% milk for total and phosphoGFAT1 blots or 4\% BSA for $O$-GlcNAc blots. Following incubation with respective horseradish peroxidase-conjugated secondary antibodies for $1 \mathrm{~h}$, signal detection was performed using enhanced chemiluminescence reagent $\left(\mathrm{ECL}^{\mathrm{TM}}\right)$. Protein bands were quantified by densitometry using ImageJ software and ratios between phosphoprotein and total protein were calculated if applicable. For quantification of relative $O$-GlcNAc levels, every $O$-GlcNAcylated protein contributing to a signal of a whole lane was quantified densitomentrically in each condition. The 
sum of all values within a condition representing relative $O$-GlcNAcylation level was compared between distinct conditions.

\section{Genetic manipulations of HUVEC}

The RNA interference (RNAi) duplex oligos against AMPK $\alpha 1$, AMPK $\alpha 2$, GFAT1 and nontargeting control-siRNA were transfected into HUVEC for $72-120 \mathrm{~h}$ using the amphiphilic delivery system SAINT-RED as described previously [33].

For expression of WT-GFAT1 and S243A-GFAT1, HUVEC were transduced using freshly prepared lentiviral particles and stable transductants were puromycin-selected. For more detailed description of the procedure, see Supplementary Material, Methods.

\section{Spheroid assay}

Spheroids were generated by mixing cells suspended in M199 growth medium (untreated HUVEC) or in M199 containing 2\% FCS (transduced HUVEC) with methyl cellulose (stock solution $12 \mathrm{mg} / \mathrm{ml}$ ) at a 4:1 ratio and by incubating 3,000 cells/well overnight in 96-well roundbottom plates. After washing with Hepes buffer including $0.75 \mathrm{mmol} / 1 \mathrm{CaCl}_{2}$ (Hepes-Ca ${ }^{2+}$ buffer), spheroids were seeded onto 24 -well plates containing $1.8 \mathrm{mg} / \mathrm{ml}$ fibrinogen in 300 $\mu 1 /$ well Hepes-Ca ${ }^{2+}$ buffer. Subsequently, thrombin (0.66 unit/well) was added to induce the formation of a fibrin gel. After washing out thrombin, spheroids were cultured in M199 containing $2 \%$ FCS and 10 or 50 ng/ml VEGF for 24 h (transduced HUVEC) or 48 h. Finally, spheroids were fixed with $4 \%$ paraformaldehyde and viewed by light microscopy. Images were captured and analysed using cellSens ${ }^{\mathrm{TM}}$ image analysis software (Olympus). Analysis of sprouting was performed with 5-10 spheroids per condition in duplicates. Absolute values of sprout number and lengths as well as differences of stimulated minus control values were compared. 


\section{Statistics}

Experimental values were expressed as percentage of control values, set as $100 \%$. Data are presented as means \pm SEM of 3-5 independent experiments. Single variables were compared between two groups using unpaired or paired two-tailed Student's $t$-test; $p<0.05$ was considered statistically significant. Statistical tests were performed and graphs were plotted using GraphPad Prism 4 software. 


\section{Results}

\section{Phosphoproteomic screen has identified potential novel AMPK-dependent targets}

In order to identify AMPK-dependent cellular targets, we applied a systematic/unbiased global high-throughput screen based on the analysis of the native environment (cellular context, no chemical modifications, unchanged kinase/substrate ratio) and a robust differentiation strategy $\left(\mathrm{AMPK} \alpha 1^{+/+} \alpha 2^{+/+}\right.$and $\mathrm{AMPK} \alpha 1^{-/-} \alpha 2^{-/-}$MEFs, specific AMPK activation) as illustrated in Supplementary Figure S1A. The identified candidate list (Table 1, Supplementary Figure S1B) included the AMPK substrate tuberous sclerosis complex 2 (TSC2) [8] evidencing the sensitivity of our screening strategy. Among the strong candidates for AMPK cellular substrates (ratio $\geq 2$ ), double cortin like protein kinase 1, armadillo repeat-containing protein 10, SAPS domain family member 3, tumor protein D54 and GFAT1 were found (Table 1, Supplementary Material, Discussion).

\section{GFAT1 is phosphorylated by AMPK at serine 243}

Mass spectrometry analysis identified a GFAT1 phosphopeptide containing serine 243 within the sequence, which perfectly complies with the AMPK consensus motif (Figure 1A). The MS1 signal for this 802.851 Th phosphopeptide was highly reproducible between the replicates in $\mathrm{AMPK} \alpha 1^{+/+} \alpha 2^{+/+}$(Figure 1B) and AMPK $\alpha 1^{-/} \alpha 2^{-/-}$MEFs (Figure 1C). The corresponding MS2 spectrum clearly assigns the phosphorylation site on serine 243: the b3 ion with a neutral loss of phosphoric acid rules out any other phosphorylatable residue (Figure 1D). GFAT1 phosphorylation by AMPK was also confirmed by in vitro phosphopeptide mapping. After AMPK kinase reaction, a trypsin digest of WT-GFAT1 yielded one radioactively labelled peptide that was absent in S243A-GFAT1 (Figure 1E, F) indicating serine 243 as single AMPK phosphorylation site. This finding was confirmed by autoradiography and immunoblotting, where phosphospecific-(Ser243)-GFAT1 antibody recognised recombinant WT-GFAT1 
phosphorylated with AMPK but not S243A-GFAT1 (Figure 1G). The stoichiometry of GFAT1 phosphorylation at serine 243 was estimated to be $33 \%$.

GFAT1 was also proven to be a cellular AMPK target since increased GFAT1 phosphorylation in response to AMPK agonists was seen only in AMPK $\alpha 1^{+/+} / \alpha 2^{+/+}$but not in AMPK $\alpha 1^{-/-} / \alpha 2^{-/-}$ MEFs, which are completely lacking AMPK activity (Supplementary Figure S2A, B). Of note, a residual phospho-GFAT1 signal was still observed in AMPK-deficient MEFs, indicating that an alternative kinase may exist. AMPK-dependent GFAT1 phosphorylation was also observed in HEK293 cells (Supplementary Figure S2C, D).

\section{AMPK phosphorylates GFAT1 in primary human endothelial cells}

Since high HBP fluxes and $O$-GlcNAc levels are known to contribute to endothelial dysfunction, we investigated the role of GFAT1 phosphorylation by AMPK in endothelial cells. We treated HUVEC with several AMPK activators, among which AICAR showed the strongest phosphorylation of GFAT1 (data not shown). The effect of AICAR on GFAT1 phosphorylation was AMPK-dependent since it was not observed in cells pretreated with AMPK $\alpha 1 / \alpha 2$-siRNA

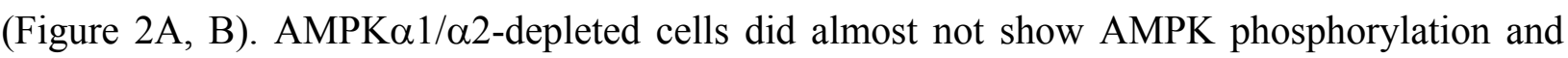
exhibited reduced phosphorylation of the canonical AMPK substrate acetyl-CoA carboxylase (Figure 2A). Importantly, when the activity of endogenous GFAT1 immunopurified from AICAR-stimulated endothelial cells was measured, a considerable decrease was observed indicating that AMPK-mediated GFAT phosphorylation has an inhibitory impact on enzyme activity (Figure 2D). Controls proving that the measured activity is attributed to GFAT are shown in Supplementary Figure S3.

Based on the results obtained with AICAR, we hypothesised that VEGF, which had been shown to trigger AMPK activation in endothelial cells [10], may affect GFAT1 as well. Indeed, phosphorylation of GFAT1 was increased in response to VEGF at time points (5-10 min) at which AMPK was activated (Figure 2E). This increase was prevented when both AMPK $\alpha 1$ and 
AMPK $\alpha 2$ were silenced (Figure 2F, G) proving that VEGF-induced GFAT1 phosphorylation was AMPK-dependent. GFAT1 phosphorylation was maintained up to $1 \mathrm{~h}$ after VEGF treatment (Supplementary Figure S4) indicating prolonged VEGF effects on HBP activity via AMPK. Together, these data demonstrate for the first time that endogenous GFAT1 is a physiological AMPK substrate in human endothelial cells and is a component of the VEGF-AMPK signaling pathway.

\section{Serine 243 of GFAT1 is responsible for AMPK effects on HBP in endothelial cells}

To understand the functional significance of the AMPK-GFAT1 signalling axis, we compared $O$ GlcNAc levels in HUVEC with modulated AMPK expression or activity. Protein $O$-GlcNAcylation was increased in AMPK $\alpha 1 / \alpha 2$-depleted HUVEC $(21 \%$ increase against control cells) (Figure 3A, B), and, in contrast, decreased in HUVEC stimulated with AICAR (56\% reduction against untreated cells) (Figure 3C, D).

In order to check whether inhibition of $O$-GlcNAcylation by AMPK is mediated via GFAT1 phosphorylation, we generated HUVEC stably expressing WT-GFAT1 or the S243A mutant (WT-HUVEC or S243A-HUVEC, respectively). GFAT1 protein levels were increased to a comparable extent and in a physiological range in both types of transductants (up to two-fold) (Figure 3E, F). Keeping transgene expression at these moderate levels preserves physiological GFAT1/AMPK ratios thus allowing studying AMPK-dependent regulation of GFAT1 and modulation of $O$-GlcNAc levels via AMPK-GFAT1 signalling. At this modest transgene expression, basal $O$-GlcNAc levels were not altered in WT- or S243A-HUVEC compared to control cells transduced using empty lentiviral vector. This is in line with a previous report showing that 2.6-fold stable overexpression of GFAT1 in NIH-3T3 fibroblasts does not increase UDP-GlcNAc levels robustly at longer culture time, possibly due to feedback mechanisms limiting GFAT1 activity [34]. 
AMPK stimulation of the generated HUVEC lines with AICAR led to a significant increase of phospho-GFAT1 in control cells and WT-HUVEC but only to a marginal alteration in S243AHUVEC (Figure 3E and G) due to residual endogenous GFAT1. Consequently, the inhibitory effect of AICAR on protein $O$-GlcNAcylation was clearly seen in control and WT-HUVEC, while it was low in HUVEC expressing S243A-GFAT1 (Figure 3E and H). In addition, a reduced inhibitory effect of AMPK on O-GlcNAc levels was observed in HEK293 cells expressing S243A-GFAT1 (Supplementary Figure S5).

Taken together, these data underline the importance of serine 243 as a target for AMPK and a mediator of AMPK effects on HBP in endothelial cells.

\section{GFAT1 controls angiogenesis}

Our group had demonstrated that AMPK $\alpha 1$ activated by VEGF mediates in vitro and in vivo angiogenesis [10]. Since GFAT1/HBP was now identified as a component of the VEGF-AMPK pathway in endothelial cells, we investigated whether it was involved in the regulation of VEGFinduced angiogenesis.

We first used the glutamine analogue DON as GFAT1 antagonist and studied its effect on angiogenesis employing a spheroid assay. Figure 4A, B show that DON significantly reduced protein $O$-GlcNAcylation under basal conditions. Importantly, treatment of endothelial spheroids with DON led to a slight increase of spontaneous sprouting and potentiated VEGF-induced sprouting by $67 \%$ compared to the VEGF effect in untreated cells (Figure 4C-E). As an approach to activate GFAT1/HBP pathway we used high glucose. Incubation of cells with high glucose for 24-72 h led to elevated protein $O$-GlcNAcylation by $31 \%$ or $75 \%$, respectively, which was counteracted by DON (Figure 4A, B). The angiogenic effect of VEGF was reduced by $36 \%$ at high glucose compared to normal glucose conditions (Figure 4C-E). Inclusion of DON to high glucose treatment brought impaired sprouting not only back to normal, but enhanced it over untreated control values (Figure 4C-E). The potentiating effect of DON in high glucose 
condition was lower than at normal glucose, possibly due to involvement of pathways apart from HBP into antiangiogenic effects of high glucose (Figure 4C-E).

Since DON also inhibits other glutamine-utilizing enzymes, we secondly applied a genetic approach to modulate GFAT1. We treated HUVEC with GFAT1-specific siRNA, which led to a significant downregulation of GFAT1 expression (Figure 5A, B). As a consequence, $O$ GlcNAcylation of proteins decreased $(32 \%$ and $48 \%$ decrease compared to controls at $72 \mathrm{~h}$ and $120 \mathrm{~h}$ post transfection, respectively) (Figure 5A and C). When GFAT1-depleted cells were utilised in spheroid assays, a trend towards spontaneous sprouting of the capillary-like structures was observed (Figure 5D-F) similarly to what had been seen with DON. Furthermore, GFAT1 downregulation significantly increased VEGF-induced sprouting by $72 \%$ compared to the VEGF effect in cells treated with control siRNA (Figure 5D-F).

Together, these data demonstrate that VEGF-induced angiogenesis is inhibited by GFAT1/HBP.

\section{GFAT1 phosphorylation at serine 243 mediates VEGF-induced pro-angiogenic effects of}

\section{AMPK}

The above described data indicate that VEGF via activation of AMPK and subsequent phosphorylation of GFAT may impair the HBP and thus relieve its inhibitory action on angiogenesis. In order to provide a proof for this, we compared VEGF-induced angiogenesis in WT-HUVEC and S243A-HUVEC. VEGF triggered a 5.4- and 5.1-fold increase of sprout number per spheroid in control and WT-HUVEC, respectively, while it caused only a 3-fold increase in S243A-HUVEC over basal levels (Figure 6A, B), meaning 40\% reduction of VEGFeffect in S243A-HUVEC compared to WT-HUVEC (Figure 6A and C).

The differences in VEGF-induced angiogenesis seen between control or WT-HUVEC and SAHUVEC correlate with the presence and absence of $O$-GlcNAcylation regulation by AMPK observed in these cells, respectively (Figure 3E and H). Thus, the reduced sprouting in S243AHUVEC can be attributed to the impaired regulation of GFAT1/HBP by the VEGF-AMPK 
pathway. These data provide unequivocal evidence that GFAT1 phosphorylation at serine 243 represents one of the mechanisms underlying pro-angiogenic effects of AMPK in response to VEGF. 


\section{Discussion}

An increase of the glucose flux through HBP and chronically elevated $O$-GlcNAcylation of target proteins is increasingly recognised as an important contributor to the pathogenesis of type 2 diabetes and its cardiovascular complications [35]. However, the regulation of the HBP and the mechanisms and functions of protein $O$-GlcNAcylation are poorly characterised. The present study reveals that AMPK, a key regulator of cellular metabolism and homeostasis, controls HBP and the abundance of $O$-GlcNAcylation in endothelial cells via targeting GFAT1, the ratelimiting enzyme of the HBP, and that this process is a part of the proangiogenic VEGF-AMPK axis.

GFAT1 was found as an AMPK target in our systematic phosphoproteomic approach aimed at identifying novel AMPK substrates. In line with this finding two previous studies have already suggested GFAT1 as an AMPK substrate employing either purified recombinant GFAT1 in vitro [13] or recombinant GFAT1 expressed in CHO cells [12]. However, the role of AMPK-mediated GFAT1 phosphorylation in regulating GFAT activity was not clear and the biological significance of this process in a physiologically relevant system had not been investigated. Our study confirms serine 243 of GFAT1 as phosphorylation site by tandem MS and as AMPK site in a range of in vitro experiments using a recombinant GFAT1 preparation. As a novel outcome of these experiments, we show that serine 243 is a single AMPK site, which is phosphorylated to a stoichiometry of $0.33 \mathrm{~mol} / \mathrm{mol}$. In addition, we validated endogenous GFAT1 as a cellular AMPK target in WT and AMPK-null MEFs as an unequivocal model for testing AMPKdependency, thus establishing GFAT1 as a direct physiological AMPK substrate. Since we detected basal serine 243 phosphorylation of GFAT1 in AMPK-null MEFs, a second kinase such as $\mathrm{Ca}^{2+} /$ calmodulin-dependent kinase II (CaMKII), which has recently been shown to phosphorylate GFAT at serine 243 in vitro [13], may share this phosphorylation site with AMPK. However, phosphorylation signals in AMPK-null MEFS were lower compared to WT MEFs suggesting that AMPK plays a major role. 
Enhanced glucose fluxes through the HBP as well as increased protein $O$-GlcNAcylation are known to contribute to endothelial dysfunction underlying the development of diabetic vasculopathies. GFAT activity has been described in primary endothelial cells of different origin and has been shown to be upregulated by hyperglycaemia [36]. In addition, while expression of GFAT was barely detected in endothelial cells of healthy human tissues, it was increased in activated cells suggesting that it may be modulated under pathophysiological conditions [37]. Given these indications, we addressed the role of the AMPK-GFAT1 axis in endothelial cells. Our study demonstrates for the first time that GFAT1 is a physiological AMPK substrate in primary human endothelial cells, as VEGF, a major physiological AMPK agonist in endothelial cells, was able to increase AMPK-dependent GFAT1 phosphorylation. Using AMPK activators and AMPK-specific siRNA, we revealed an inhibitory effect of AMPK on $O$-GlcNAc levels, which is most likely due to inhibition of GFAT1 activity by AMPK-mediated phosphorylation, since activity of GFAT was decreased in cells treated with the AMPK activator. In line with this, a recent study showed that metformin and AICAR cause an AMPK-dependent reduction of UDP-GlcNAc in NIH3T3 cells [38].

To further verify the functional importance of AMPK-dependent GFAT1 phosphorylation, we performed experiments with cells expressing S243A-GFAT1. In these cells, AMPK activation led to a lower reduction of cellular $O$-GlcNAc levels as compared to control cells, thus confirming the inhibitory role of serine 243 phosphorylation for GFAT1 activity. The fact that the inhibitory effects of AMPK were only partially prevented by the S243A mutant could be due to residual endogenous GFAT1 and/or GFAT-independent effects of AMPK on metabolic branches which supply $O$-GlcNAc production, e.g. glycolysis or fatty acid oxidation. Our data are in line with the study of Eguchi et al., who showed that GFAT1 activity was decreased after activating cellular AMPK by treatment with 2-deoxyglucose [12] indicating a possible inhibitory role of serine 243 phosphorylation for GFAT1 activity. In contrast, Li et al. observed an activation of recombinant GFAT1 after serine 243 phosphorylation by AMPK in vitro [13]. This 
discrepancy may be due to the lack of endogenous regulatory factors, e.g. allosteric regulators of GFAT1 or different posttranslational modifications, when recombinant proteins are employed. Importantly, our study extends the study by Eguchi et al. [12] by providing cellular $O$ GlcNAcylation data and showing that the AMPK-GFAT1 regulatory axis is coupled to $O$ GlcNAc signalling. The observed degree of reduction in protein $O$-GlcNAcylation after AMPK activation seems to be moderate, which is in line with $33 \%$ stoichiometry of GFAT1 phosphorylation. However, even a modest alteration of $O$-GlcNAcylation can have functional consequences as shown for the microtubule-associated protein tau. Changes in tau $O$ GlcNAcylation in the range of $20-30 \%$ led to significant alteration of its phosphorylation state and may be involved in tau pathology in the context of Alzheimer disease [39-41]. Given that the $O$-GlcNAc machinery is tightly controlled by negative regulatory feedback loops at the level of GFAT1 $[31,42]$ and $O$-GlcNAc transferase (OGT) [43], our data support the view that AMPK has an important function in controlling $O$-GlcNAc levels. In line with this, AMPK depletion led also to de novo O-GlcNAcylation of proteins. Interestingly, AMPK has also been shown to phosphorylate OGT, the enzyme responsible for $O$-GlcNAcylation, thereby determining its substrate selectivity [44]. Thus, AMPK is regulating the $O$-GlcNAcylation machinery at different levels.

The major question of the present study was if GFAT1 regulation by AMPK plays a biological role in endothelial cells. Previous data obtained in our group revealed that AMPK $\alpha 1$ is required for VEGF-induced in vitro and in vivo angiogenesis [10], but the underlying mechanisms were completely unknown. The present data suggest that GFAT1 phosphorylation by AMPK represents a previously unknown pro-angiogenic pathway. Pharmacological inhibition or siRNAmediated downregulation of GFAT1 led to increased VEGF-induced sprouting of endothelial spheroids indicating that inhibition of GFAT1 by AMPK-mediated phosphorylation promotes angiogenesis. Indeed, when this phosphorylation was prevented by introducing S243A-GFAT1 into endothelial cells, VEGF-induced angiogenesis was decreased. Our data indicate that $O$ - 
GlcNAcylation patterns essentially modulate the angiogenic response of endothelial cells to VEGF with high levels of $O$-GlcNAcylated proteins leading to inhibition of angiogenesis. In line with this, several studies have correlated $O$-GlcNAcylation with possible anti-angiogenic effects. For example, $O$-GlcNAcylation of the proangiogenic enzyme eNOS induced decreased enzyme activity $[45,46]$ and $O$-GlcNAcylation of Akt was suggested to negatively affect migration and tube formation of endothelial cells [47]. Furthermore, $O$-GlcNAcylation of Sp1 leads to elevated expression of $\mathrm{TGF}_{1}$ (an inducer of extracellular matrix protein synthesis) and PAI-1 (an inhibitor of extracellular matrix degradation) [48], while $O$-GlcNAcylation of Sp3 promotes angiopoietin-2 expression, which in turn triggers increased expression of ICAM-1 and VCAM-1 [49].

Our data demonstrate that high glucose induces impairment of VEGF-stimulated in vitro angiogenesis and that this effect was counteracted by pharmacological inhibition of GFAT1 with DON. These data are in line with a study by Luo et al. who showed that high fat diet or streptozotocin injections in vivo or glucosamine treatment in vitro reduced sprouting from aortic rings, which was associated with increased $O$-GlcNAc tissue levels [47]. In this study, $O$ GlcNAcase overexpression prevented the adverse effects of hyperglycaemia on angiogenesis. Together, our data and the data of Luo et al. demonstrate that stimulation of the HBP and elevated $O$-GlcNAcylation of proteins are implicated in high glucose-induced inhibition of angiogenesis. This in turn may contribute to cardiovascular complications in diabetes such as impaired wound healing, reduced myocardial perfusion or even organ dysfunction as observed in the islets of Langerhans (reviewed in $[50,51]$ ).

The interpretation of the current study is limited since the results were obtained in vitro using HUVEC as a model. Although HUVEC have been widely used to characterise endothelial functions they may differ from adult cells of different vascular beds and may be influenced by maternal and foetal factors. However, the HUVEC spheroid model has recently been characterised as a sensitive tool to study angiogenesis and provides reliable results if it is 
performed under standardised conditions [52]. In addition to HUVEC we have shown AMPKmediated GFAT1 phosphorylation in other cell lines (HEK293, MEFs) suggesting that this pathway is of general importance. Future experiments need to involve animal models of diabetes as well as ex vivo methodologies for evaluating endothelial cells from patients [53]. Moreover, to reveal the causal involvement of reduced $O$-GlcNAcylation, the respective protein targets need to be identified and the effect of mutating the sites of modification on protein function needs to be investigated.

In summary, we conclude that modulation of angiogenesis via interference with the HBP may help to prevent or ameliorate the clinical sequelae of hyperglycaemia. In this context, targeting AMPK, which was shown to control HBP via GFAT in our study, may represent a promising vasculoprotective strategy. 


\section{Author Contribution}

D.Z., F.V., K.S., R.H. conceived the study. F.V. setup, performed and analysed the phosphoproteomic screen (supervised by N.A.M, K.S.) and carried out in vitro validation (supervised by K.S.). D.Z. performed and analysed cellular validation (supervised by K.S.) and experiments using endothelial cells (supervised by R.H). O.G. performed initial cellular validation of recombinant GFAT1. M.P. performed cloning and generated GFAT1 expression constructs. K.M. provided valuable advices regarding GFAT1 and sugar nucleotide biology. A.K. and K.Sp. contributed to generation/characterisation of stable HUVEC lines. C.W. provided GFAT1 anti-serum and helpful advices. B.V. provided AMPK WT and AMPK-null MEF. D.Z., F.V., K.S., R.H. wrote the manuscript. All authors discussed the results and commented on the manuscript. R.H. is the guarantor of this work and, as such, had full access to all the data in the study and takes responsibility for the integrity of the data and the accuracy of the data analysis.

\section{Funding}

This work was supported by Medical Research Council and the pharmaceutical companies supporting the Division of Signal Transduction Therapy Unit (AstraZeneca, BoehringerIngelheim, GlaxoSmithKline, Merck KGaA, Janssen Pharmaceutica and Pfizer). F.V. was funded by grant from RASOR (Radical Solutions for Researching the proteome, Scotland), an Interdisciplinary Research Collaboration Initiative between the Biotechnology and Biological

Sciences Research Council, the Engineering and Physical Sciences Research Council and the Scottish Funding Council (UK). R.H. was funded by the DFG (Deutsche Forschungsgemeinschaft), RTG 1715, subproject 2, and RTG 2155, subproject 13.

\section{Competing Interests}

The Authors declare that there are no competing interests associated with the manuscript. 


\section{Acknowledgements}

We thank Elke Teuscher (Institute for Molecular Cell Biology, Center for Molecular Biomedicine, University Hospital Jena) for excellent assistance with the isolation and culture of HUVEC. We are grateful to Dr. D. Grahame Hardie (University of Dundee, UK) for providing recombinant AMPK trimeric complex and AMPKal antibody, and to Dr. Jörg Müller (Jena University Hospital, Germany) for supplying packaging plasmids and lentivectors. 


\section{References}

1 Steinberg, G. R. and Kemp, B. E. (2009) AMPK in Health and Disease. Physiol Rev. 89, $1025-1078$

2 Scott, J. W., Ling, N., Issa, S. M., Dite, T. A., O'Brien, M. T., Chen, Z. P., Galic, S., Langendorf, C. G., Steinberg, G. R., Kemp, B. E. and Oakhill, J. S. (2014) Small molecule drug A-769662 and AMP synergistically activate naive AMPK independent of upstream kinase signaling. Chem Biol. 21, 619-627

3 Xiao, B., Sanders, M. J., Underwood, E., Heath, R., Mayer, F. V., Carmena, D., Jing, C., Walker, P. A., Eccleston, J. F., Haire, L. F., Saiu, P., Howell, S. A., Aasland, R., Martin, S. R., Carling, D. and Gamblin, S. J. (2011) Structure of mammalian AMPK and its regulation by ADP. Nature. 472, 230-233

4 Gowans, G. J., Hawley, S. A., Ross, F. A. and Hardie, D. G. (2013) AMP is a true physiological regulator of AMP-activated protein kinase by both allosteric activation and enhancing net phosphorylation. Cell Metab. 18, 556-566

5 Merrill, G. F., Kurth, E. J., Hardie, D. G. and Winder, W. W. (1997) AICA riboside increases AMP-activated protein kinase, fatty acid oxidation, and glucose uptake in rat muscle. Am J Physiol. 273, E1107-1112

6 Munday, M. R., Campbell, D. G., Carling, D. and Hardie, D. G. (1988) Identification by amino acid sequencing of three major regulatory phosphorylation sites on rat acetyl-CoA carboxylase. Eur J Biochem. 175, 331-338

7 Gwinn, D. M., Shackelford, D. B., Egan, D. F., Mihaylova, M. M., Mery, A., Vasquez, D. S., Turk, B. E. and Shaw, R. J. (2008) AMPK phosphorylation of raptor mediates a metabolic checkpoint. Mol Cell. 30, 214-226

8 Inoki, K., Zhu, T. and Guan, K. L. (2003) TSC2 mediates cellular energy response to control cell growth and survival. Cell. 115, 577-590

9 Fisslthaler, B. and Fleming, I. (2009) Activation and signaling by the AMP-activated protein kinase in endothelial cells. Circ Res. 105, 114-127

10 Stahmann, N., Woods, A., Spengler, K., Heslegrave, A., Bauer, R., Krause, S., Viollet, B., Carling, D. and Heller, R. (2010) Activation of AMP-activated protein kinase by vascular endothelial growth factor mediates endothelial angiogenesis independently of nitric-oxide synthase. J Biol Chem. 285, 10638-10652

11 Oki, T., Yamazaki, K., Kuromitsu, J., Okada, M. and Tanaka, I. (1999) cDNA cloning and mapping of a novel subtype of glutamine:fructose-6-phosphate amidotransferase (GFAT2) in human and mouse. Genomics. 57, 227-234

12 Eguchi, S., Oshiro, N., Miyamoto, T., Yoshino, K., Okamoto, S., Ono, T., Kikkawa, U. and Yonezawa, K. (2009) AMP-activated protein kinase phosphorylates glutamine : fructose-6phosphate amidotransferase 1 at Ser243 to modulate its enzymatic activity. Genes Cells. 14, 179189 
13 Li, Y., Roux, C., Lazereg, S., LeCaer, J. P., Laprevote, O., Badet, B. and Badet-Denisot, M. A. (2007) Identification of a novel serine phosphorylation site in human glutamine:fructose6-phosphate amidotransferase isoform 1. Biochemistry. 46, 13163-13169

14 Banko, M. R., Allen, J. J., Schaffer, B. E., Wilker, E. W., Tsou, P., White, J. L., Villen, J., Wang, B., Kim, S. R., Sakamoto, K., Gygi, S. P., Cantley, L. C., Yaffe, M. B., Shokat, K. M. and Brunet, A. (2011) Chemical genetic screen for AMPKalpha2 substrates uncovers a network of proteins involved in mitosis. Mol Cell. 44, 878-892

15 Hardiville, S. and Hart, G. W. (2014) Nutrient regulation of signaling, transcription, and cell physiology by O-GlcNAcylation. Cell Metab. 20, 208-213

16 Cooksey, R. C., Hebert, L. F., Jr., Zhu, J. H., Wofford, P., Garvey, W. T. and McClain, D. A. (1999) Mechanism of hexosamine-induced insulin resistance in transgenic mice overexpressing glutamine:fructose-6-phosphate amidotransferase: decreased glucose transporter GLUT4 translocation and reversal by treatment with thiazolidinedione. Endocrinology. 140, $1151-1157$

17 Hazel, M., Cooksey, R. C., Jones, D., Parker, G., Neidigh, J. L., Witherbee, B., Gulve, E. A. and McClain, D. A. (2004) Activation of the hexosamine signaling pathway in adipose tissue results in decreased serum adiponectin and skeletal muscle insulin resistance. Endocrinology. 145, 2118-2128

18 Hebert, L. F., Jr., Daniels, M. C., Zhou, J., Crook, E. D., Turner, R. L., Simmons, S. T., Neidigh, J. L., Zhu, J. S., Baron, A. D. and McClain, D. A. (1996) Overexpression of glutamine:fructose-6-phosphate amidotransferase in transgenic mice leads to insulin resistance. J Clin Invest. 98, 930-936

19 Srinivasan, V., Sandhya, N., Sampathkumar, R., Farooq, S., Mohan, V. and Balasubramanyam, M. (2007) Glutamine fructose-6-phosphate amidotransferase (GFAT) gene expression and activity in patients with type 2 diabetes: inter-relationships with hyperglycaemia and oxidative stress. Clin Biochem. 40, 952-957

20 Ma, J. and Hart, G. W. (2013) Protein O-GlcNAcylation in diabetes and diabetic complications. Expert Rev Proteomics. 10, 365-380

21 Laczy, B., Hill, B. G., Wang, K., Paterson, A. J., White, C. R., Xing, D., Chen, Y. F., Darley-Usmar, V., Oparil, S. and Chatham, J. C. (2009) Protein O-GlcNAcylation: a new signaling paradigm for the cardiovascular system. Am J Physiol Heart Circ Physiol. 296, H13-28

22 Goransson, O., McBride, A., Hawley, S. A., Ross, F. A., Shpiro, N., Foretz, M., Viollet, B., Hardie, D. G. and Sakamoto, K. (2007) Mechanism of action of A-769662, a valuable tool for activation of AMP-activated protein kinase. J Biol Chem. 282, 32549-32560

23 Weigert, C., Klopfer, K., Kausch, C., Brodbeck, K., Stumvoll, M., Haring, H. U. and Schleicher, E. D. (2003) Palmitate-induced activation of the hexosamine pathway in human myotubes: increased expression of glutamine:fructose-6-phosphate aminotransferase. Diabetes. 52, 650-656

24 Jokela, T. A., Makkonen, K. M., Oikari, S., Karna, R., Koli, E., Hart, G. W., Tammi, R. H., Carlberg, C. and Tammi, M. I. (2011) Cellular content of UDP-N-acetylhexosamines controls hyaluronan synthase 2 expression and correlates with O-linked $\mathrm{N}$-acetylglucosamine modification of transcription factors YY1 and SP1. J Biol Chem. 286, 33632-33640 
25 Laderoute, K. R., Amin, K., Calaoagan, J. M., Knapp, M., Le, T., Orduna, J., Foretz, M. and Viollet, B. (2006) 5'-AMP-activated protein kinase (AMPK) is induced by low-oxygen and glucose deprivation conditions found in solid-tumor microenvironments. Mol Cell Biol. 26, 5336-5347

26 Towler, M. C. and Hardie, D. G. (2007) AMP-activated protein kinase in metabolic control and insulin signaling. Circ Res. 100, 328-341

27 Heller, R., Unbehaun, A., Schellenberg, B., Mayer, B., Werner-Felmayer, G. and Werner, E. R. (2001) L-ascorbic acid potentiates endothelial nitric oxide synthesis via a chemical stabilization of tetrahydrobiopterin. J Biol Chem. 276, 40-47

28 Reihill, J. A., Ewart, M. A., Hardie, D. G. and Salt, I. P. (2007) AMP-activated protein kinase mediates VEGF-stimulated endothelial NO production. Biochem Biophys Res Commun. 354, 1084-1088

29 Kommaddi, R. P., Dickson, K. M. and Barker, P. A. (2011) Stress-induced expression of the p75 neurotrophin receptor is regulated by O-GlcNAcylation of the Sp1 transcription factor. $\mathrm{J}$ Neurochem. 116, 396-405

30 Ostrowski, A. and van Aalten, D. M. (2013) Chemical tools to probe cellular O-GlcNAc signalling. Biochem J. 456, 1-12

31 Broschat, K. O., Gorka, C., Page, J. D., Martin-Berger, C. L., Davies, M. S., Huang Hc, H. C., Gulve, E. A., Salsgiver, W. J. and Kasten, T. P. (2002) Kinetic characterization of human glutamine-fructose-6-phosphate amidotransferase I: potent feedback inhibition by glucosamine 6-phosphate. J Biol Chem. 277, 14764-14770

32 Badet, B., Vermoote, P., Haumont, P. Y., Lederer, F. and LeGoffic, F. (1987) Glucosamine synthetase from Escherichia coli: purification, properties, and glutamine-utilizing site location. Biochemistry. 26, 1940-1948

33 Stahmann, N., Woods, A., Carling, D. and Heller, R. (2006) Thrombin activates AMPactivated protein kinase in endothelial cells via a pathway involving $\mathrm{Ca} 2+/$ calmodulin-dependent protein kinase kinase beta. Mol Cell Biol. 26, 5933-5945

34 Weigert, C., Brodbeck, K., Lehmann, R., Haring, H. U. and Schleicher, E. D. (2001) Overexpression of glutamine:fructose-6-phosphate-amidotransferase induces transforming growth factor-beta1 synthesis in NIH-3T3 fibroblasts. FEBS Lett. 488, 95-99

35 Buse, M. G. (2006) Hexosamines, insulin resistance, and the complications of diabetes: current status. Am J Physiol Endocrinol Metab. 290, E1-E8

36 Wu, G., Haynes, T. E., Yan, W. and Meininger, C. J. (2001) Presence of glutamine:fructose-6-phosphate amidotransferase for glucosamine-6-phosphate synthesis in endothelial cells: effects of hyperglycaemia and glutamine. Diabetologia. 44, 196-202

37 Nerlich, A. G., Sauer, U., Kolm-Litty, V., Wagner, E., Koch, M. and Schleicher, E. D. (1998) Expression of glutamine:fructose-6-phosphate amidotransferase in human tissues: evidence for high variability and distinct regulation in diabetes. Diabetes. 47, 170-178

38 Ishibashi, Y. and Hirabayashi, Y. (2015) AMP-activated Protein Kinase Suppresses Biosynthesis of Glucosylceramide by Reducing Intracellular Sugar Nucleotides. J Biol Chem. 290, 18245-18260 
39 Li, X., Lu, F., Wang, J. Z. and Gong, C. X. (2006) Concurrent alterations of OGlcNAcylation and phosphorylation of tau in mouse brains during fasting. Eur J Neurosci. 23, 2078-2086

40 Liu, F., Iqbal, K., Grundke-Iqbal, I., Hart, G. W. and Gong, C. X. (2004) OGlcNAcylation regulates phosphorylation of tau: a mechanism involved in Alzheimer's disease. Proc Natl Acad Sci U S A. 101, 10804-10809

41 Zhu, Y., Shan, X., Yuzwa, S. A. and Vocadlo, D. J. (2014) The emerging link between O-GlcNAc and Alzheimer disease. J Biol Chem. 289, 34472-34481

42 Kornfeld, R. (1967) Studies on L-glutamine D-fructose 6-phosphate amidotransferase. I. Feedback inhibition by uridine diphosphate-N-acetylglucosamine. J Biol Chem. 242, 3135-3141

43 Taylor, R. P., Geisler, T. S., Chambers, J. H. and McClain, D. A. (2009) Up-regulation of O-GlcNAc transferase with glucose deprivation in HepG2 cells is mediated by decreased hexosamine pathway flux. J Biol Chem. 284, 3425-3432

44 Bullen, J. W., Balsbaugh, J. L., Chanda, D., Shabanowitz, J., Hunt, D. F., Neumann, D. and Hart, G. W. (2014) Cross-talk between two essential nutrient-sensitive enzymes: O-GlcNAc transferase (OGT) and AMP-activated protein kinase (AMPK). J Biol Chem. 289, 10592-10606

45 Du, X. L., Edelstein, D., Dimmeler, S., Ju, Q., Sui, C. and Brownlee, M. (2001) Hyperglycemia inhibits endothelial nitric oxide synthase activity by posttranslational modification at the Akt site. J Clin Invest. 108, 1341-1348

46 Federici, M., Menghini, R., Mauriello, A., Hribal, M. L., Ferrelli, F., Lauro, D., Sbraccia, P., Spagnoli, L. G., Sesti, G. and Lauro, R. (2002) Insulin-dependent activation of endothelial nitric oxide synthase is impaired by O-linked glycosylation modification of signaling proteins in human coronary endothelial cells. Circulation. 106, 466-472

47 Luo, B., Soesanto, Y. and McClain, D. A. (2008) Protein modification by O-linked GlcNAc reduces angiogenesis by inhibiting Akt activity in endothelial cells. Arterioscler Thromb Vasc Biol. 28, 651-657

48 Du, X. L., Edelstein, D., Rossetti, L., Fantus, I. G., Goldberg, H., Ziyadeh, F., Wu, J. and Brownlee, M. (2000) Hyperglycemia-induced mitochondrial superoxide overproduction activates the hexosamine pathway and induces plasminogen activator inhibitor-1 expression by increasing Sp1 glycosylation. Proc Natl Acad Sci U S A. 97, 12222-12226

49 Yao, D., Taguchi, T., Matsumura, T., Pestell, R., Edelstein, D., Giardino, I., Suske, G., Rabbani, N., Thornalley, P. J., Sarthy, V. P., Hammes, H. P. and Brownlee, M. (2007) High glucose increases angiopoietin-2 transcription in microvascular endothelial cells through methylglyoxal modification of mSin3A. J Biol Chem. 282, 31038-31045

50 Eberhard, D., Kragl, M. and Lammert, E. (2010) 'Giving and taking': endothelial and beta-cells in the islets of Langerhans. Trends Endocrinol Metab. 21, 457-463

51 Kolluru, G. K., Bir, S. C. and Kevil, C. G. (2012) Endothelial dysfunction and diabetes: effects on angiogenesis, vascular remodeling, and wound healing. Int J Vasc Med. 2012, 918267

52 Heiss, M., Hellstrom, M., Kalen, M., May, T., Weber, H., Hecker, M., Augustin, H. G. and Korff, T. (2015) Endothelial cell spheroids as a versatile tool to study angiogenesis in vitro. FASEB J. 29, 3076-3084 
53 Onat, D., Brillon, D., Colombo, P. C. and Schmidt, A. M. (2011) Human vascular endothelial cells: a model system for studying vascular inflammation in diabetes and atherosclerosis. Curr Diab Rep. 11, 193-202 
Table 1. Mass spectrometry characteristics of the identified phosphopeptides containing the AMPK consensus sequence.

For each AMPK consensus motif-containing phosphopeptide, the following parameters are summarised: the peptide sequence, the IPI accession number, the corresponding Uniprot accession number, the gene symbol, the description of the protein, the experimental mass over charge ( $\mathrm{m} / \mathrm{z}$ exp), the calculated neutral mass (M calc), the charge, the calculated mass over charge $(\mathrm{m} / \mathrm{z}$ calc), the mass deviation in ppm, the Mascot Score, the type of fraction (IMAC or TiO2), the ratio of MS1 signal intensities of the same phosphopeptide in $\mathrm{AMPK} \alpha 1^{+/+} / \alpha 2^{+/+} v s$. AMPK $\alpha 1^{-/ /} / \alpha 2^{-/}$MEF after AMPK activation and ratio standard deviation (SD). IPI database being discontinued, corresponding UniProtKB accession were added to the table.

\begin{tabular}{|c|c|c|c|c|c|c|c|c|c|c|c|c|c|}
\hline peptide & IPI accession & $\begin{array}{c}\text { SP } \\
\text { accession }\end{array}$ & $\begin{array}{c}\text { gene } \\
\text { symbol }\end{array}$ & description & $\mathrm{m} / \mathrm{z}(\exp )$ & M (calc) & charge & $\mathrm{m} / \mathbf{z}$ (calc) & ppm & score & fraction & ratio & SD \\
\hline R.DLYRPLpSSDDLDSVGDSV & IPI00761729 & Q9JLM8 & $D c \mid k 1$ & Double cortin like protein kinase 1 & $1,016.945$ & $2,031.867$ & 2 & $1,016.941$ & 3.5 & 70 & TiO2 & 12.6 & 0.8 \\
\hline R.DLYRPLpSpSDDLDSVGDSV & IPI00761729 & Q9JLM8 & Dclk1 & Double cortin like protein kinase 1 & $1,056.927$ & $2,111.834$ & 2 & $1,056.924$ & 2.5 & 63 & IMAC & 4.5 & 0.8 \\
\hline LRPSR.pSAEDLTDGSYDDILNAEQLK & IPI00757909 & Q9D0L7 & Armc10 & Armadillo repeat-containing protein 10 & $1,139.000$ & $2,275.973$ & 2 & $1,138.994$ & 5.5 & 119 & TiO2 & 4.0 & 0.3 \\
\hline LRPSR.pSAEDLTDGSYDDILNAEQLKK & IPI00757909 & Q9D0L7 & Armc10 & Armadillo repeat-containing protein 10 & 802.366 & $2,404.068$ & 3 & 802.363 & 3.1 & 64 & TiO2 & 3.9 & 2.1 \\
\hline GLSR.VDPSTTCLFPVEEK.A & IPI00406371 & P47856 & Gfpt1 & Glucosamine-fructose-6-phosphate aminotransferase 1 & 802.851 & $1,603.684$ & 2 & 802.849 & 2.3 & 67 & $\mathrm{TiO}_{2}$ & 3.9 & 0.3 \\
\hline R.NTVDLVTTCHIHSpSpSDDEIDFK & IPI00719971 & G5E8R4 & Ppp6r3 & Isoform 3 of SAPS domain family member 3 & 925.024 & $2,772.043$ & 3 & 925.022 & 2.3 & 37 & IMAC & 3.2 & 0.4 \\
\hline VMR.NSApTFKSFEDR & IPI00319046 & Q9CYZ2 & Tpd5212 & Tumor protein D54 & 691.293 & $1,380.571$ & 2 & 691.293 & 0.9 & 54 & $\mathrm{TiO} 2$ & 3.0 & 0.1 \\
\hline IRSTR.pSVENLPECGITHEQR & IPI00341034 & Q8BKC8 & Pik4cb & Phosphatidylinositol 4-kinase beta & 616.937 & $1,847.787$ & 3 & 616.936 & 0.3 & 37 & TiO2 & 2.6 & 0.6 \\
\hline MRRR.RpSSDPLGDTASNLGS & IPI00453615 & Q7TMY8 & Huwe1 & E3 ubiquitin-protein ligase HUWE1 & 778.832 & $1,555.652$ & 2 & 778.833 & -2.0 & 26 & TiO2 & 2.4 & 0.5 \\
\hline IRSTR.pSVENLPECGITHEQR & IPI00341034 & Q8BKC8 & Pik4cb & Phosphatidylinositol 4-kinase beta & 924.903 & $1,847.787$ & 2 & 924.901 & 2.3 & 63 & TiO2 & 2.4 & 0.2 \\
\hline FR.IEDPSEPHIPLIDDTDAEDDAPTK & IPI00556827 & G5E829 & Atp2b1 & Plasma membrane calcium ATPase 1 & 872.715 & $2,615.116$ & 3 & 872.713 & 3.2 & 53 & TIO2 & 2.3 & 0.4 \\
\hline LVR.KDPSEEEVSLLGNQDIEEGNSR & IPI00135975 & P15920 & Atp6v0a2 & Vacuolar proton translocating ATPase $116 \mathrm{kDa}$ subunit a isoform 2 & 810.024 & $2,427.044$ & 3 & 810.022 & 2.4 & 58 & TiO2 & 2.3 & 0.2 \\
\hline LSK.SSPSSPELQTLQDILGDLGDK & IPI00468568 & Q61037 & $T s c 2$ & Tuberous sclerosis 2 isoform 2 & 728.344 & $2,182.004$ & 3 & 728.342 & 2.7 & 33 & $\mathrm{TiO}_{2}$ & 2.2 & 0.1 \\
\hline FR.IEDpSEPHIPLIDDpTDAEDDAPTK & IPI00556827 & G5E829 & Atp2b1 & Plasma membrane calcium ATPase 1 & 899.704 & $2,695.083$ & 3 & 899.368 & 373.5 & 39 & IMAC & 2.1 & 0.1 \\
\hline VR.EEApSDDDMEGDEAVVR & IPI00420329 & Q6P4T2 & Snrnp200 & U5 small nuclear ribonucleoprotein $200 \mathrm{kDa}$ helicase & 923.840 & $1,845.661$ & 2 & 923.838 & 2.2 & 70 & TiO2 & 2.1 & 0.1 \\
\hline R.NTVDLVTTCHIHSpSpSDDEIDFK & IPI00719971 & G5E8R4 & Ppp6r3 & Isoform 3 of SAPS domain family member 3 & 898.368 & $2,692.077$ & 3 & 898.366 & 2.5 & 59 & IMAC & 2.0 & 0.3 \\
\hline RPR.FpSHSYLpSDSDTEAK & IPI00649326 & B2RRE2 & Myo18a & Isoform 3 of Myosin-XVIIIa & 873.820 & $1,745.622$ & 2 & 873.818 & 1.5 & 34 & IMAC & 2.0 & 0.3 \\
\hline K.LNFAVASRKTFSHELPSDFGLEpST & IPI00230108 & P27773 & Pdia3 & Protein disulfide-isomerase $\mathrm{A} 3$ & 679.797 & $2,715.198$ & 4 & 679.807 & -14.5 & 32 & TiO2 & 1.8 & 0.2 \\
\hline GPRGDN.ASpSLEDLVLK & IPI00454140 & Q6NZR5 & Skiv2l & superkiller viralicidic activity 2-like & 577.789 & $1,153.563$ & 2 & 577.789 & 0.0 & 29 & TiO2 & 1.8 & 0.1 \\
\hline LEKR.ApSGQAFELILPSPR & IPI00475138 & P54227 & Stmn1 & Stathmin 1 & 774.848 & $1,547.679$ & 2 & 774.847 & 1.8 & 45 & IMAC & 1.8 & 0.2 \\
\hline FR.IEDpSEPHIPLIDDTDAEDDAPpTKR & IPI00556827 & G5E829 & Atp2b1 & Plasma membrane calcium ATPase 1 & 924.750 & $2,771.217$ & 3 & 924.746 & 3.3 & 47 & TIO2 & 1.7 & 0.1 \\
\hline LEK.RApSGQAFELILPSPR & IPI00475138 & P54227 & Stmn1 & Stathmin 1 & 852.899 & $1,703.780$ & 2 & 852.897 & 2.0 & 56 & IMAC & 1.7 & 0.1 \\
\hline LEK.RApSGQAFELILPSPR & IPI00475138 & P54227 & Stmn1 & Stathmin 1 & 568.934 & $1,703.780$ & 3 & 568.934 & 0.2 & 30 & IMAC & 1.7 & 0.2 \\
\hline K.LVpSFHDDpSDEDLLHI & IPI00308971 & Q07113 & $\operatorname{lgf} 2 r$ & Cation-independent mannose-6-phosphate receptor precursor & 957.883 & $1,913.749$ & 2 & 957.882 & 1.8 & 43 & IMAC & 1.6 & 0.3 \\
\hline LEK.LKpSKEpSLQEAGK & IPI00137194 & P53986 & Slc16a1 & Monocarboxylate transporter 1 & 739.339 & $1,476.663$ & 2 & 739.339 & 0.2 & 35 & IMAC & 1.4 & 0.3 \\
\hline LV.SFHDDpSDEDLLHI & IPI00308971 & Q07113 & $\operatorname{lgf2r}$ & Cation-independent mannose-6-phosphate receptor precursor & 811.824 & $1,621.630$ & 2 & 811.822 & 2.8 & 25 & TiO2 & 1.3 & 0.5 \\
\hline LLR.SPPSWEPFR & IPI00128522 & P14602 & Hspb1 & Isoform A of Heat-shock protein beta-1 & 543.727 & $1,084.438$ & 2 & 543.226 & 924.4 & 47 & TiO2 & 1.2 & 0.1 \\
\hline R.MScFpSRPSMpSPTPLDR & IPI00225062 & Q8BT18 & Srrm2 & Serine/arginine repetitive matrix protein 2 & 676.932 & $2,027.771$ & 3 & 676.931 & 1.4 & 29 & IMAC & 1.2 & 0.2 \\
\hline TQVSITAAIPHLKpTpSpTLPPLPLPPLLPGDDDmDpSPKETL & IPI00460706 & Q14AX6 & Crkrs & Cdc2-related kinase, arginine/serine-rich & 743.359 & 4,454.046 & 6 & 743.348 & 13.7 & 33 & TiO2 & 1.0 & 0.4 \\
\hline VGK.ISVpSSDSVSTLNSEDFV & IPI00378156 & A2AWA9 & Rabgap1 & Isoform 1 of Rab GTPase-activating protein 1 & 623.271 & $1,864.798$ & 3 & 622.607 & 1068.7 & 31 & IMAC & 1.0 & 0.0 \\
\hline IR.HGEPSAWNLENR & IPI00457898 & Q9DBJ1 & Pgam1 & Phosphoglycerate mutase 1 & 696.790 & $1,391.562$ & 2 & 696.788 & 1.9 & 56 & TiO2 & 1.0 & 0.1 \\
\hline K.SIFREEPSPLR.I & IPI00620639 & Q8K019 & Bclaf1 & BCL2-associated transcription factor 1 isoform 3 & 657.316 & $1,312.618$ & 2 & 657.316 & 0.5 & 26 & TiO2 & 0.8 & 0.2 \\
\hline LGR.EPpSEDSLSGQKGDSVSK & IPI00675666 & Q9WVR4 & Fxr2 & Fragile $\mathrm{X}$ mental retardation syndrome-related protein 2 & 610.599 & $1,828.773$ & 3 & 610.598 & 0.7 & 27 & TiO2 & 0.8 & 0.1 \\
\hline GMAK.NGpSEADIDESLYSR & IPI00123313 & Q02053 & Ube1x & Ubiquitin-activating enzyme $\mathrm{E} 1 \mathrm{X}$ & 818.331 & $1,634.646$ & 2 & 818.330 & 0.8 & 49 & TiO2 & 0.7 & 0.2 \\
\hline R.IQpSLELDKLGpTpSELL & IPI00468726 & Q9QWY8 & Asap1 & ARF1 GTPase-activating protein & 633.621 & $1,897.813$ & 3 & 633.612 & 14.3 & 27 & $\mathrm{TiO2}$ & 0.4 & 0.2 \\
\hline
\end{tabular}




\section{Figure legends}

\section{Figure 1. Identification and validation of GFAT1 as direct AMPK target.}

(A) GFAT1 phosphopeptide (in bold letters) complies with AMPK consensus sequence [26] (box; $\phi, \beta, \mathrm{X}$ are hydrophobic, basic, and any amino acid, respectively; the residues in brackets are in any order). (B, C) Extracted ion chromatograms in quadruplicates showing the intensities of the MS1 signal for the GFAT1 phosphopeptide in AMPK $\alpha 1^{+/+} \alpha 2^{+/+}(\mathbf{B})$ and AMPK $\alpha 1^{-/-} \alpha 2^{-/-}$ (C) MEFs. (D) Fragmentation spectrum of the GFAT1 phosphopeptide. (E, F) Recombinant WT-GFAT1 (E) and S243A-GFAT1 (F) were treated with AMPK for phospho-site mapping. (F) Autoradiography/colloidal blue staining and immunoblot analysis after kinase reaction.

\section{Figure 2. AMPK activation phosphorylates and inhibits GFAT1 in HUVEC.}

(A and F) Immunoblot analysis of HUVEC transfected with non-targeting (control) or AMPK $\alpha 1 / \alpha 2$-specific $(\alpha 1 / \alpha 2)$ siRNA and treated with AICAR (A, 2 mmol/1, 1h), VEGF (F, 50 ng/ml, $5 \mathrm{~min}$ ) or vehicle (-) as control. (B and G) Densitometric analysis of phospho-GFAT1 levels in $\mathbf{A}$ and $\mathbf{F}$, respectively. (C) Evaluation of siRNA-mediated AMPK knockdown in $\mathbf{A}$ and F. (D) Upper panel - determination of glutaminase activity of GFAT immunoprecipitated from cells treated with AICAR (2 mM) or vehicle (-) for 6 h. Lower panel - phosphorylation state of immunoprecipitated GFAT1 analysed after the enzymatic reaction. (E) Immunoblot analysis of HUVEC treated with $50 \mathrm{ng} / \mathrm{ml}$ VEGF. Representative blots are shown; densitometry data are presented as means \pm SEM, n=3-6. GFAT activity was measured in duplicated/condition using cells from three independent donors. Statistical analysis was performed using unpaired Student's $t$-test. $* * * \mathrm{p}<0.001,{ }^{*} \mathrm{p}<0.05$ vs. respective controls. 


\section{Figure 3. Serine 243 of GFAT1 mediates AMPK effects on $O$-GIcNAc levels in HUVEC.}

(A and C) Immunoblot analysis of HUVEC transfected with non-targeting (control) or AMPK $\alpha 1 / \alpha 2(\alpha 1 / \alpha 2)$ siRNA (A) or treated with 2 mmol/1 AICAR or vehicle (-) for $6 \mathrm{~h}(\mathbf{C})$. (B and D) Densitometric analysis of $O$-GlcNAcylation in $\mathbf{A}$ and $\mathbf{C}$, respectively. (E) Immunoblot analysis of control, WT- and S243A-HUVEC treated with $2 \mathrm{mmol} / 1$ AICAR or vehicle (-) for 6 h. (F-H) Densitometric analysis of immunoblots shown in (E), total GFAT (F), phospho-GFAT1 (G) and $O$-GlcNAc levels $(\mathbf{H})$. Representative blots are shown; densitometry data are presented as means $\pm \mathrm{SEM}, \mathrm{n}=3$. Statistical analysis was performed using unpaired Student's $t$-test. ${ }^{*} \mathrm{p}<0.05,{ }^{*} \mathrm{p}<0.01,{ }^{* * *} \mathrm{p}<0.001$ vs. respective vehicle controls; ${ }^{\dagger} \mathrm{p}<0.05,{ }^{\S} \mathrm{p}<0.05$ GFAT1 levels in WT- and SA-HUVEC, respectively, vs. control cells.

\section{Figure 4. Pharmacological inhibition of GFAT1 improves VEGF-induced in vitro} angiogenesis.

(A) Immunoblot analysis of protein $O$-GlcNAcylation in HUVEC cultured at normal or high glucose (Glc) in the presence or absence of DON. In parallel, the same samples were run on another gel and blotted with $\beta$-actin antibody as internal control. (B) Densitometric analysis of protein $O$-GlcNAcylation shown in (A). (C-E) HUVEC spheroids stimulated with VEGF (10 $\mathrm{ng} / \mathrm{ml}, 48 \mathrm{~h}$ ) under normal or high glucose in the presence or absence of DON. Representative images of spheroids (C) and analysis of the number of sprouts per spheroid shown as absolute (D) or as VEGF minus basal values $(\mathbf{E})$. Densitometry data are means \pm SEM, $n=3$. Spheroid data are means \pm SEM, $\mathrm{n}=5$. Statistical analysis was performed using unpaired Student's $t$-test. ${ }^{\dagger} \mathrm{p}<0.05,{ }^{\dagger \dagger} \mathrm{p}<0.015 .5 \mathrm{mM}$ vs. $25 \mathrm{mM} \mathrm{Glc},{ }^{*} \mathrm{p}<0.05,{ }^{*} \mathrm{p}<0.01, * * * \mathrm{p}<0.001$ vs. respective vehicle control. 
Figure 5. siRNA-mediated depletion of GFAT1 increased VEGF-induced in vitro angiogenesis.

(A) Immunoblot analysis of HUVEC transfected with non-targeting (control) or GFAT1 siRNA. (B, C) Densitometric analysis of immunoblots shown in (A), total GFAT (B) and O-GlcNAc levels (C). (D-F) Spheroids prepared from HUVEC transfected with control or GFAT1 siRNA for $72 \mathrm{~h}$ and treated with VEGF (10 ng/ml, $24 \mathrm{~h})$. Representative images of spheroids (D) and analysis of the number of sprouts per spheroid shown as absolute (E) or as VEGF minus basal values $(\mathbf{F})$. Densitometry data are means \pm SEM, $n=3$. Spheroid data are means $\pm \mathrm{SEM}, \mathrm{n}=5$. Statistical analysis was performed using unpaired Student's $t$-test. ${ }^{*} \mathrm{p}<0.05, * * \mathrm{p}<0.01$, $* * * p<0.001 v s$. respective vehicle control.

Figure 6. Serine 243 of GFAT1 mediates VEGF-induced pro-angiogenic effect of AMPK.

(A-D) Spheroids from control, WT- and S243A-HUVEC lines were stimulated with $10 \mathrm{ng} / \mathrm{ml}$ VEGF for $48 \mathrm{~h}$. Representative images (A) and analysis of the number of sprouts per spheroid shown as absolute $(\mathbf{B})$ or as VEGF minus basal values $(\mathbf{C})$ are presented. Data are means $\pm \mathrm{SEM}$, $\mathrm{n}=3$. Statistical analysis was performed using paired (B) or unpaired (C) Student's $t$-test. ${ }^{*} \mathrm{p}<0.05,{ }^{*} \mathrm{p}<0.01$ vs. respective vehicle control, ${ }^{\dagger} \mathrm{p}<0.05$ VEGF-induced sprouting in S243AHUVEC $v s$. VEGF-induced sprouting in WT-HUVEC. 
Figure 1

A

B

C

Protein Peptide sequence Ratio

GFAT1 [GLSR]VDPSTTCLFPVEEK

3.9

$\phi[\beta, X] \times X S / T X X X \phi$

D

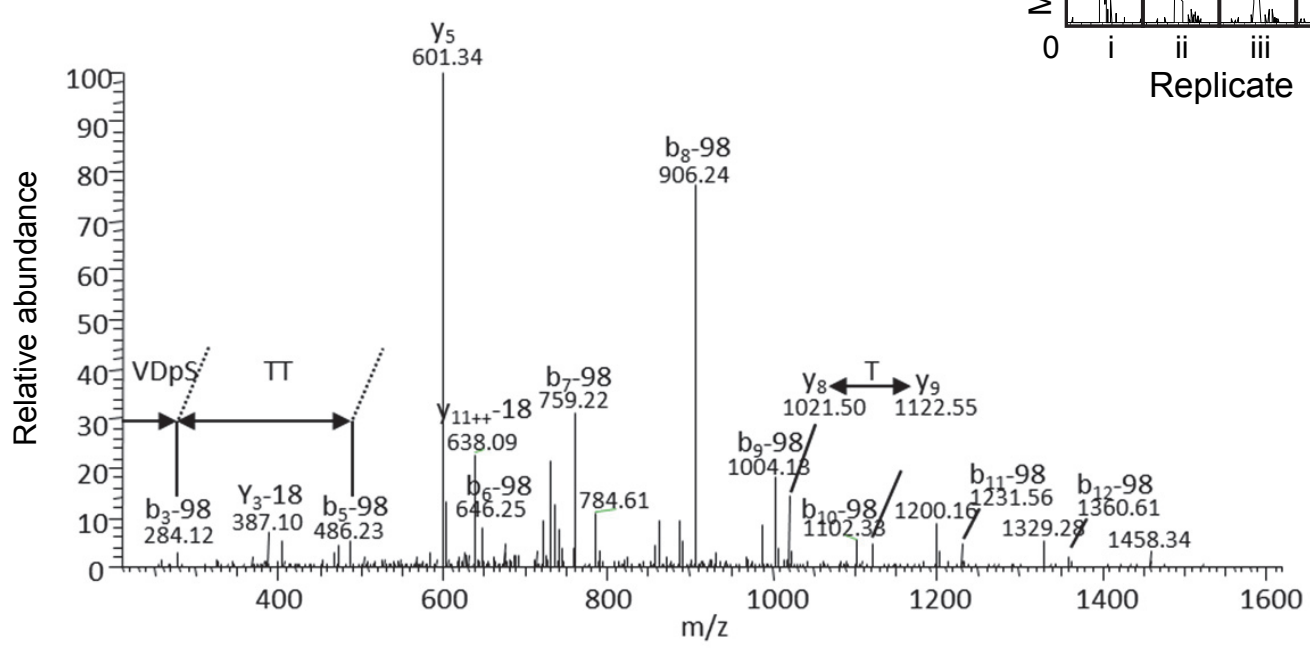

$E$
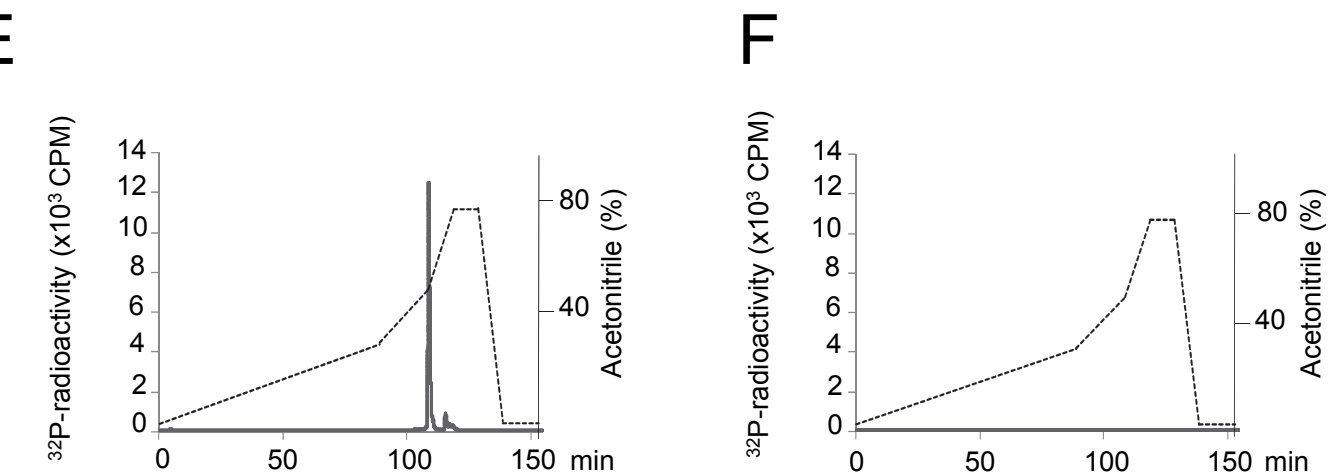

G
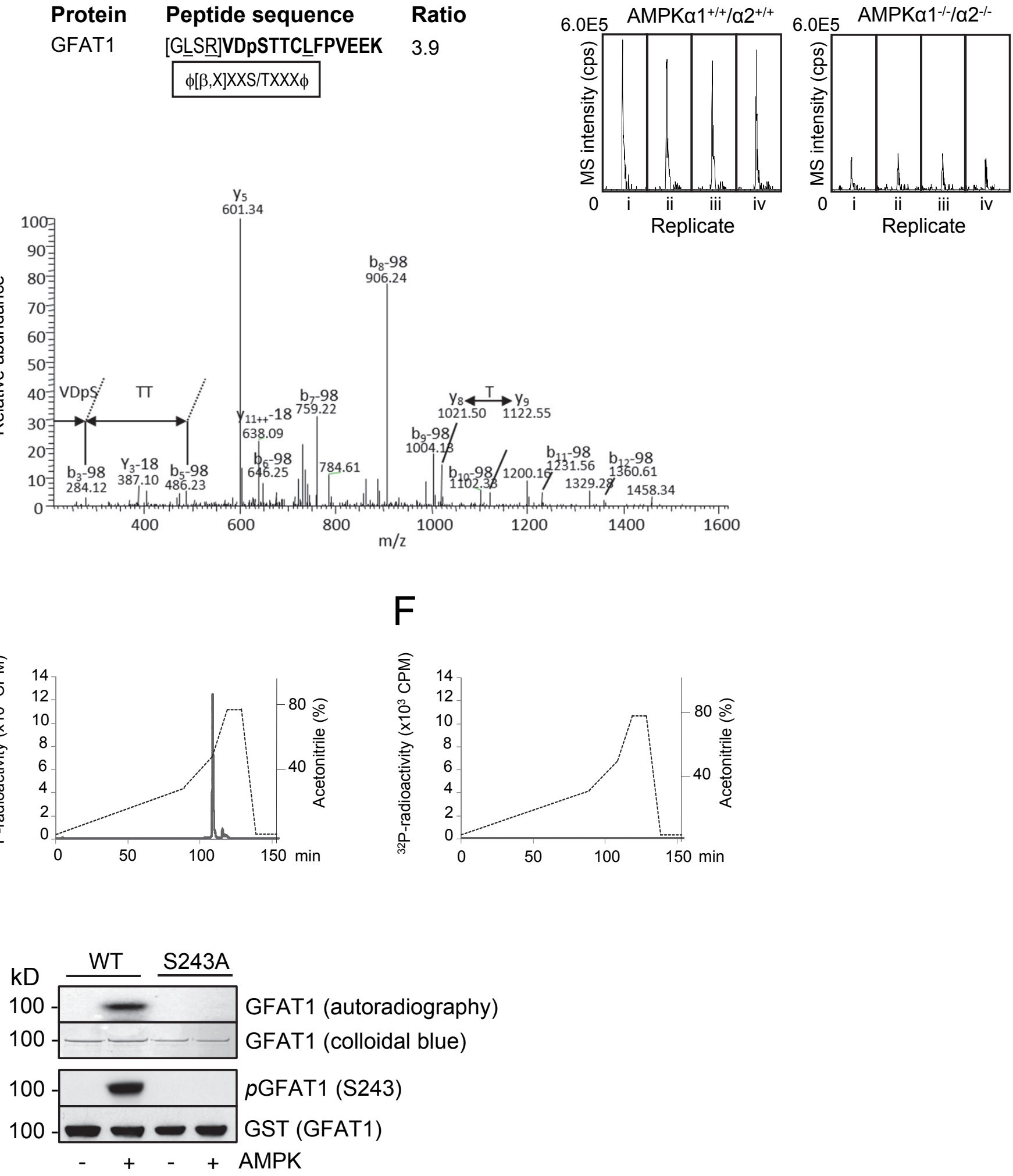
Figure 2

A

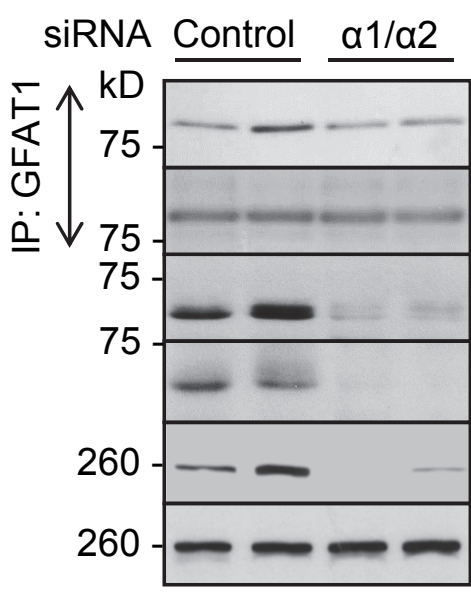

AICAR - + - +
B
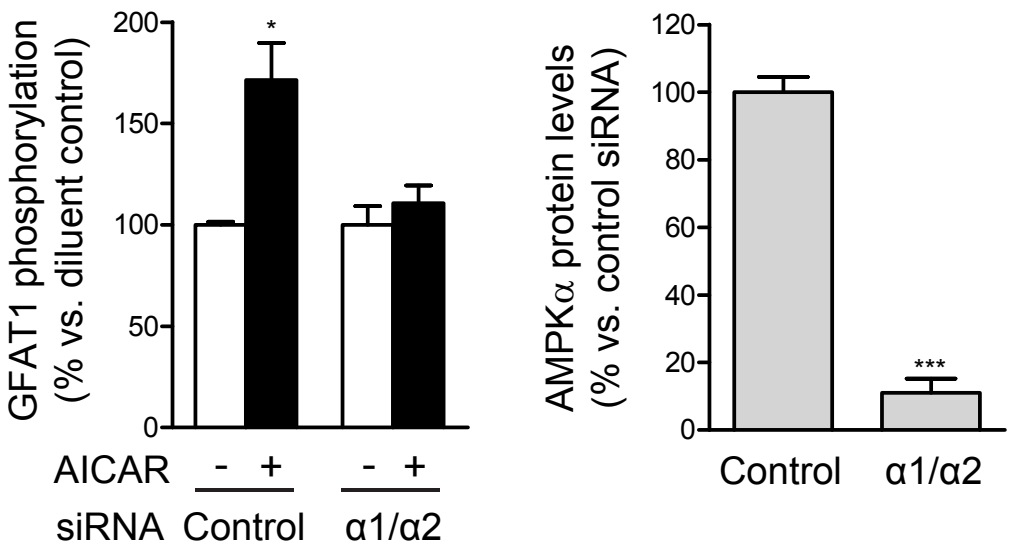

D

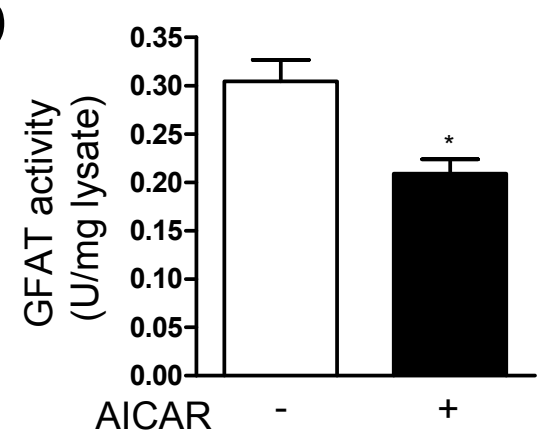

pGFAT1/GFAT1 $1 \quad 1.65 \pm 0.1$

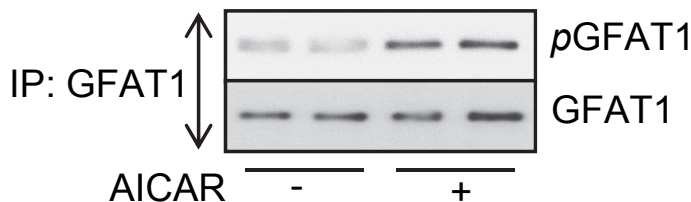

$\mathrm{F}$

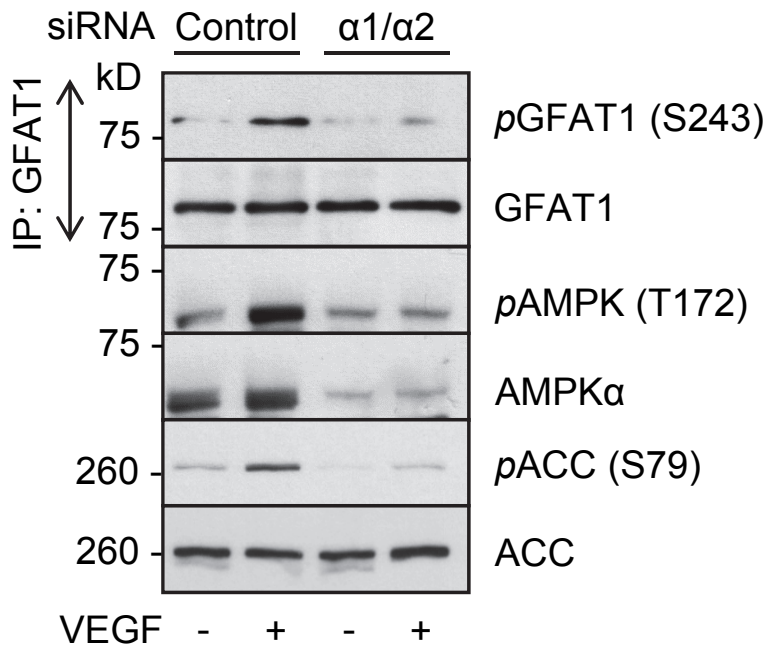

$E$

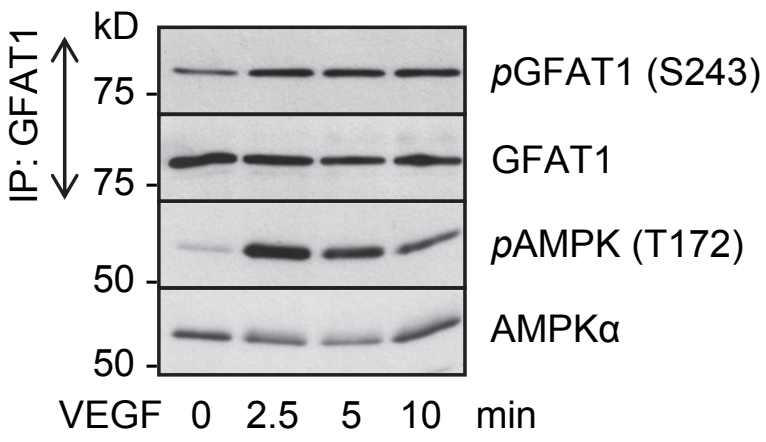

G

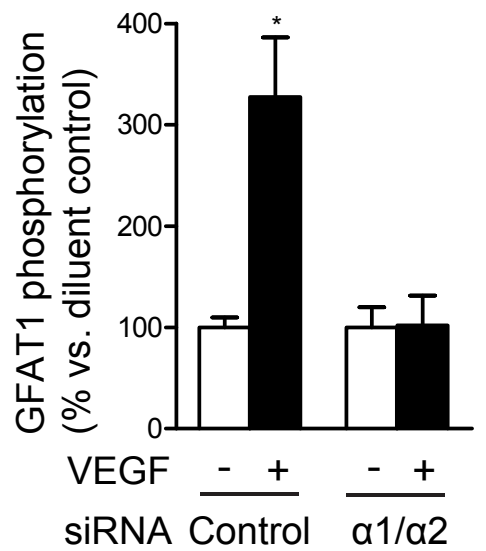


Figure 3
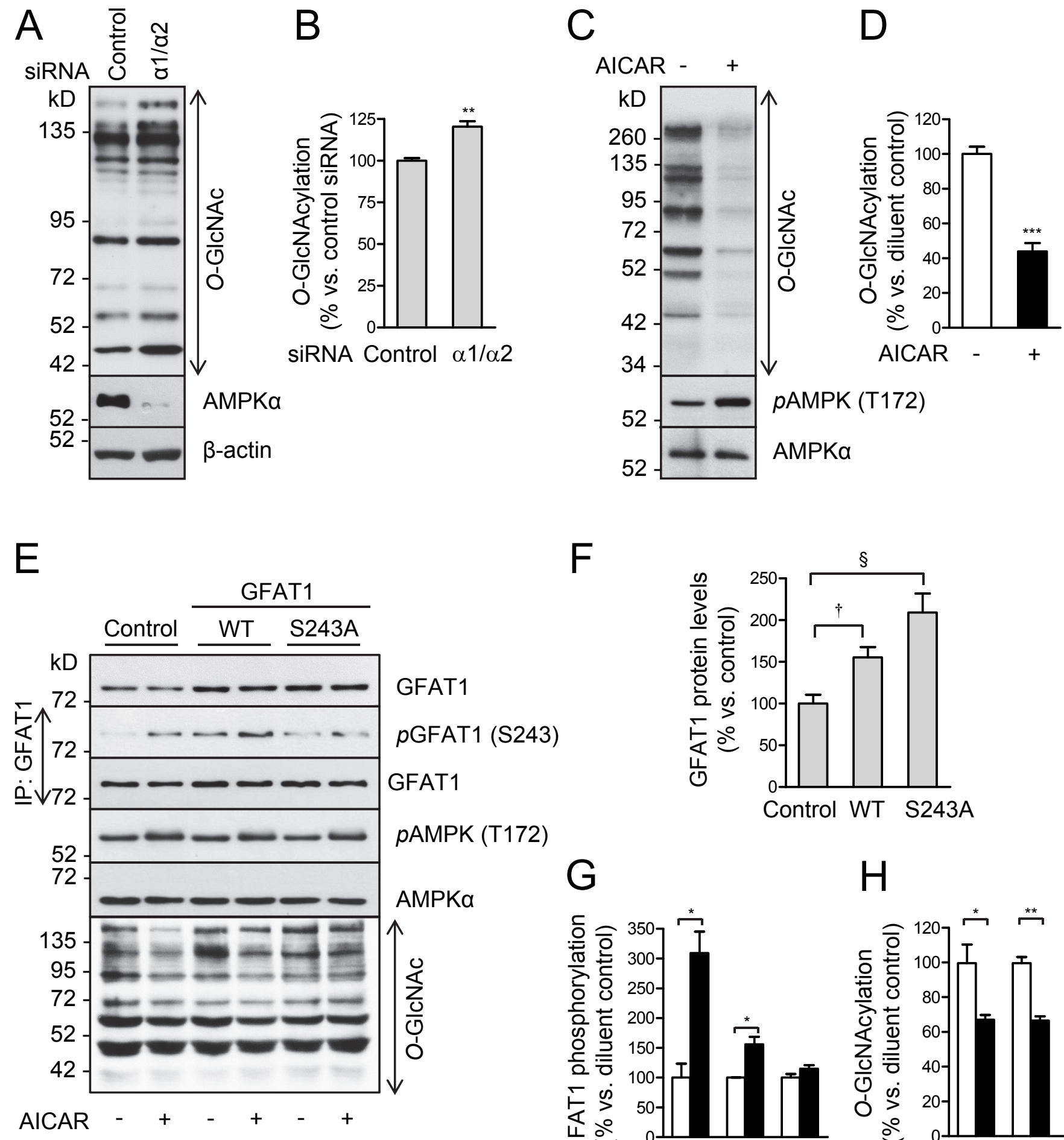

F
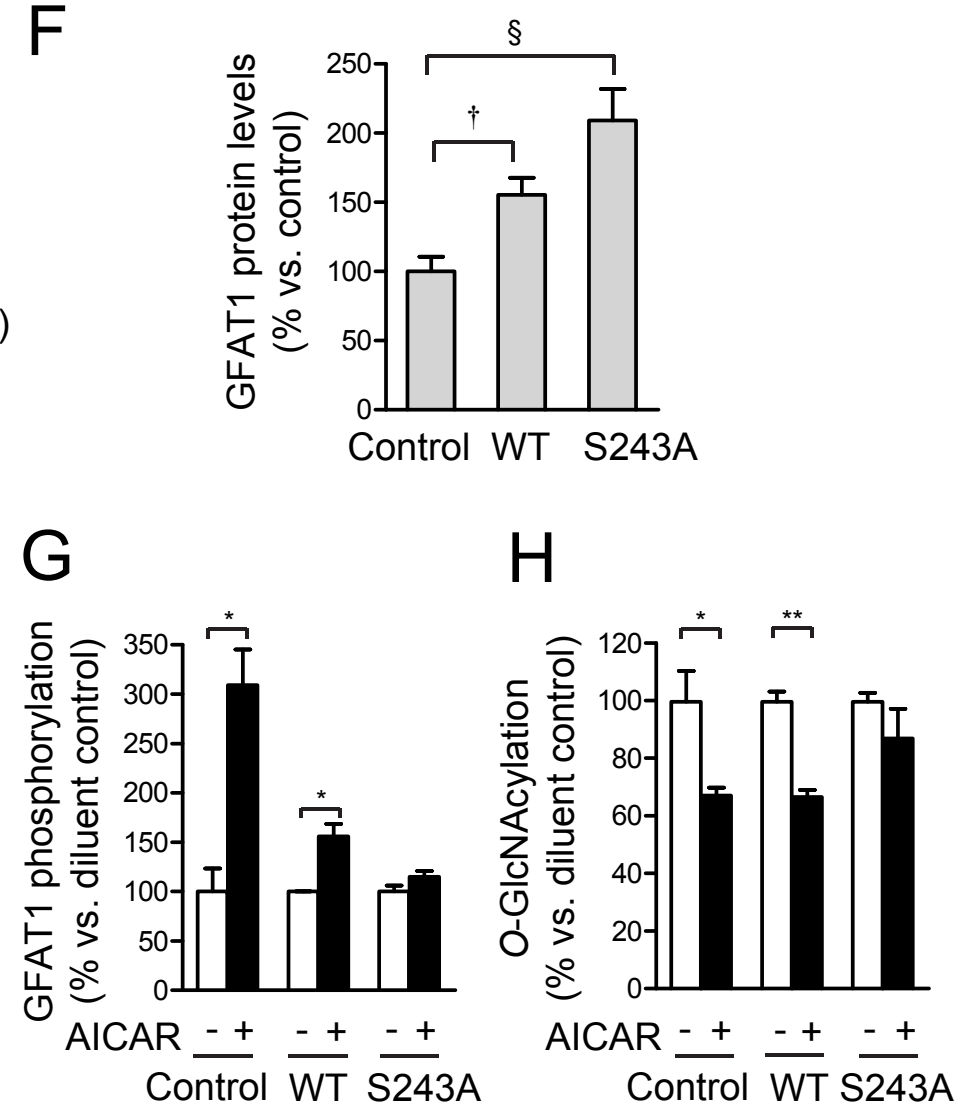
Figure 4

A

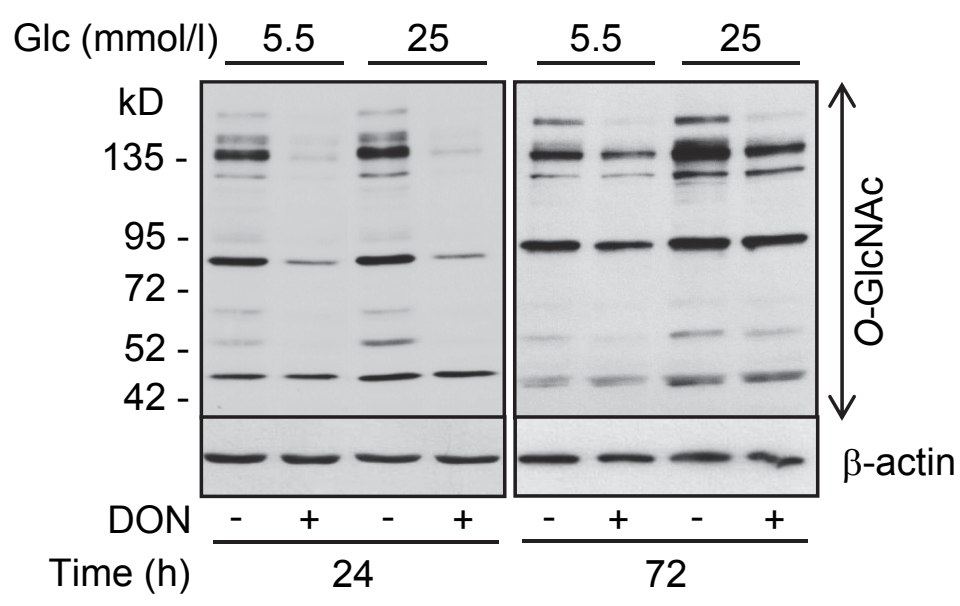

B

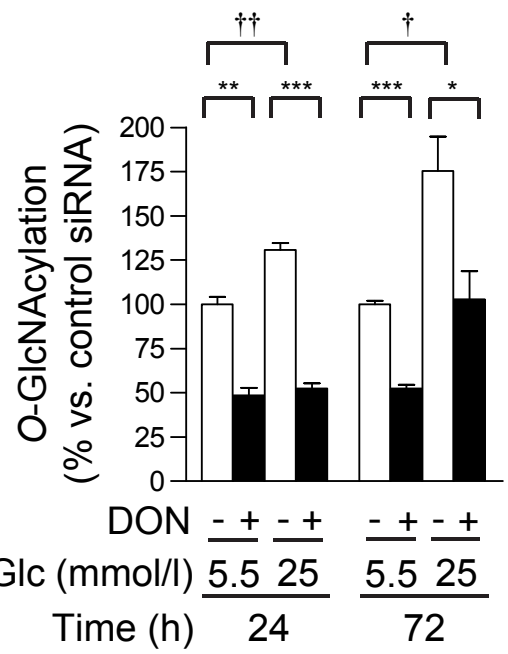

C

$5.5 \mathrm{mmol} / \mathrm{l} \mathrm{Glc}$

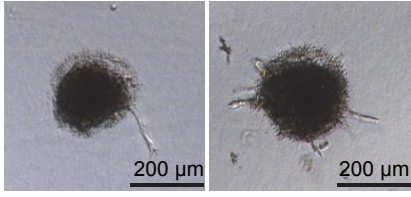

$25 \mathrm{mmol} / \mathrm{l} \mathrm{Glc}$

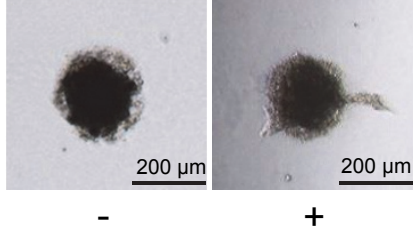

D

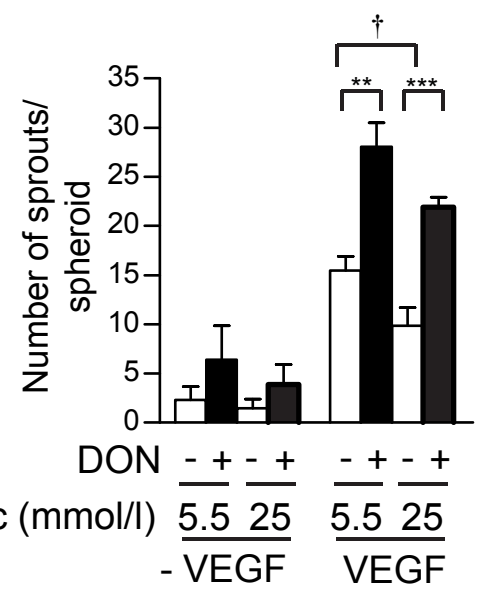

VEGF
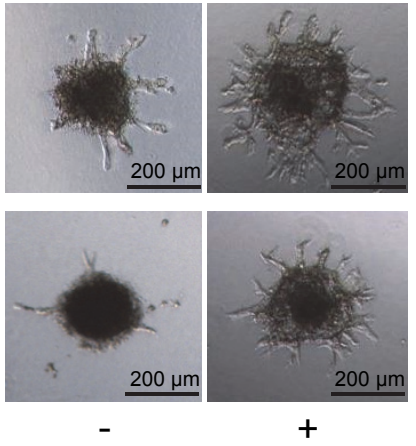

E

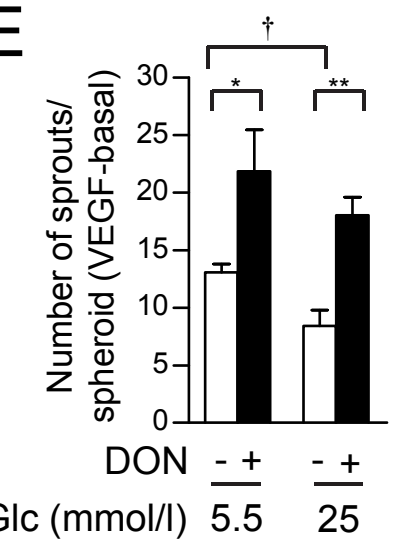


Figure 5

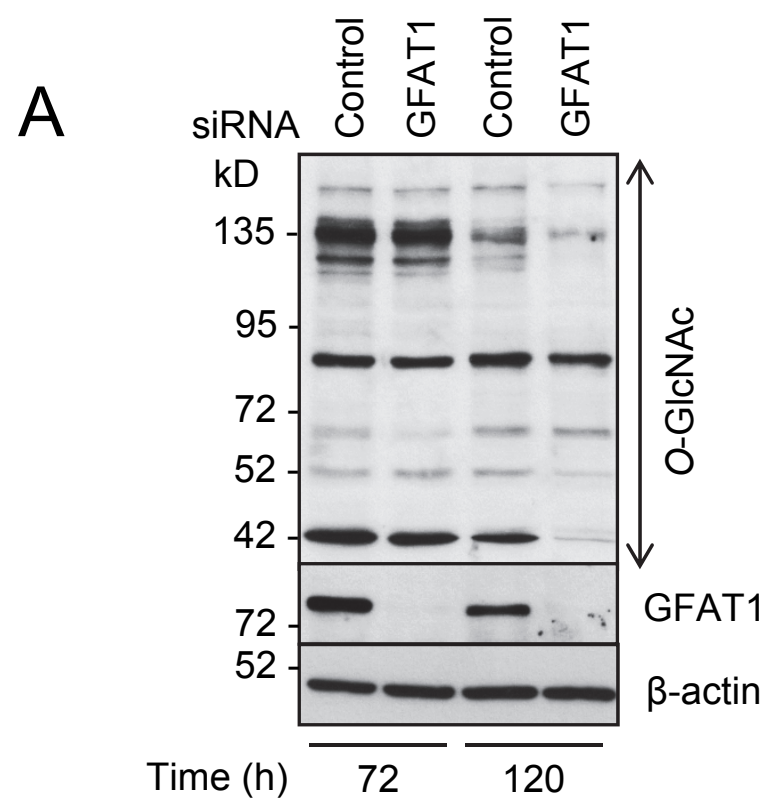

B

C
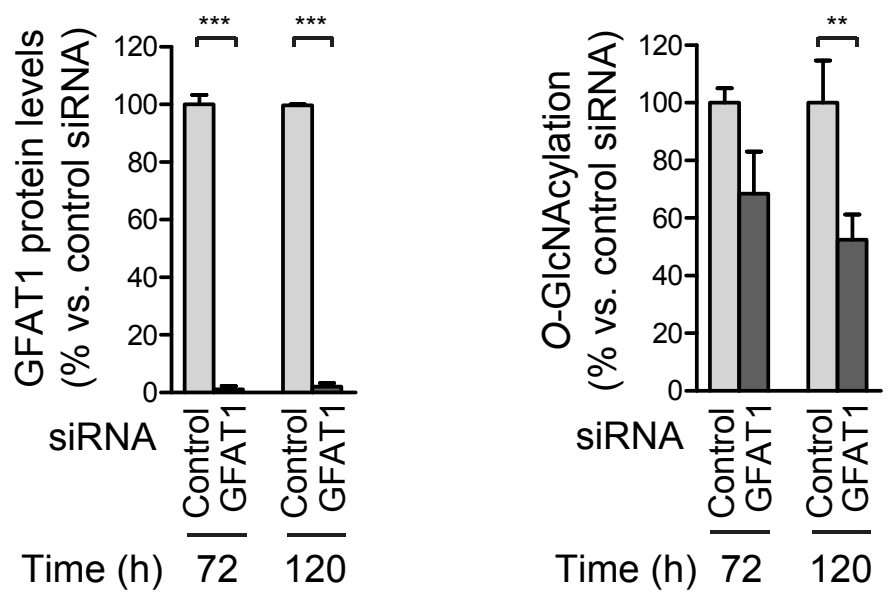

D

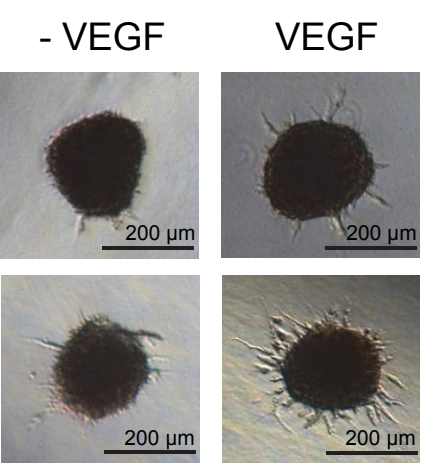

E

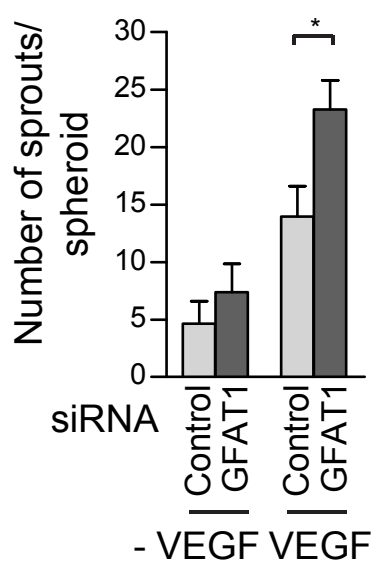

F

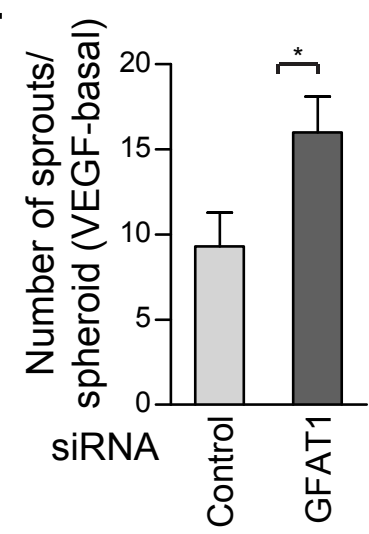


Figure 6

A
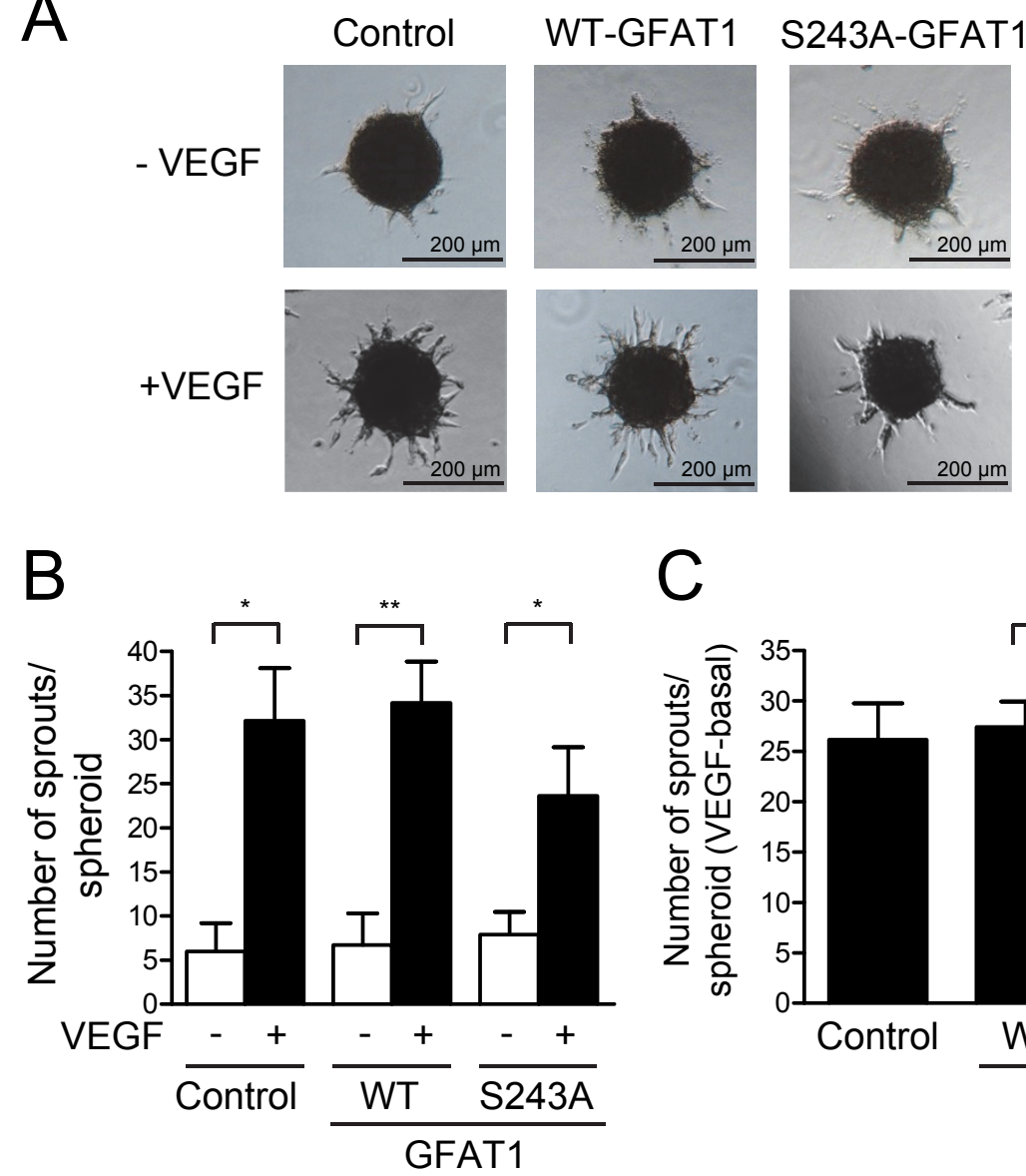

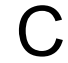
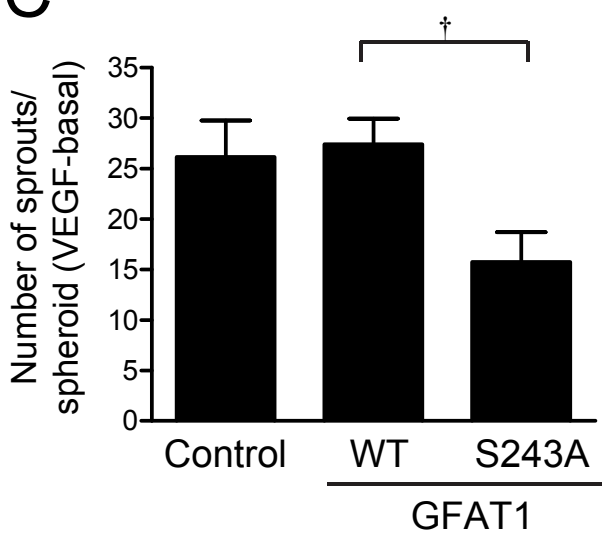